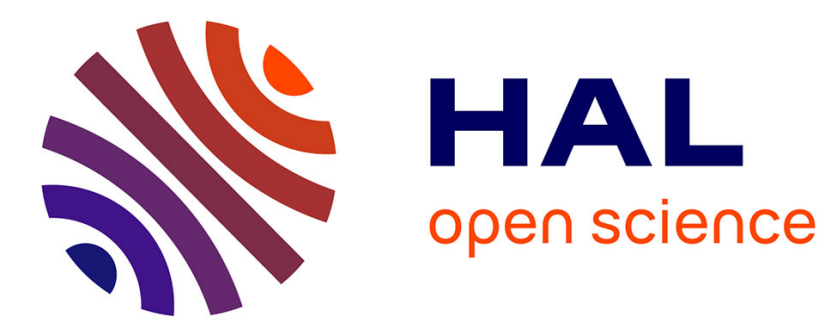

\title{
Environmental factors controlling soil organic carbon stability in French forest soils
}

Laure Soucémarianadin, Lauric Cécillon, Bertrand Guenet, Claire Chenu, François Baudin, Manuel Nicolas, Cyril Girardin, Pierre Barré

\section{- To cite this version:}

Laure Soucémarianadin, Lauric Cécillon, Bertrand Guenet, Claire Chenu, François Baudin, et al.. Environmental factors controlling soil organic carbon stability in French forest soils. Plant and Soil, 2018, 426 (1-2), pp.267-286. 10.1007/s11104-018-3613-x . hal-01744147

HAL Id: hal-01744147

https://hal.science/hal-01744147

Submitted on 27 Mar 2018

HAL is a multi-disciplinary open access archive for the deposit and dissemination of scientific research documents, whether they are published or not. The documents may come from teaching and research institutions in France or abroad, or from public or private research centers.
L'archive ouverte pluridisciplinaire HAL, est destinée au dépôt et à la diffusion de documents scientifiques de niveau recherche, publiés ou non, émanant des établissements d'enseignement et de recherche français ou étrangers, des laboratoires publics ou privés. 
1 Environmental factors controlling soil organic carbon stability in French forest

2 soils

5 Laure N. Soucémarianadin ${ }^{1, *}$, Lauric Cécillon ${ }^{2}$, Bertrand Guenet ${ }^{3}$, Claire Chenu ${ }^{4}$, François

6 Baudin $^{5}$, Manuel Nicolas ${ }^{6}$, Cyril Girardin ${ }^{4}$ and Pierre Barré ${ }^{1}$

7

$8{ }^{1}$ Laboratoire de Géologie, PSL Research University, CNRS-ENS UMR8538, Paris, France

$9 \quad{ }^{2}$ Université Grenoble Alpes, Irstea, UR LESSEM, St-Martin-d'Hères, France

$10{ }^{3}$ Laboratoire des Sciences du Climat et de l'Environnement, LSCE/IPSL, CEA-CNRS-

11 UVSQ, Université Paris-Saclay, Gif-sur-Yvette, France

$12{ }^{4}$ AgroParisTech-INRA, UMR ECOSYS, Thiverval-Grignon, France

$13{ }^{5}$ Sorbonne-Université/UPMC, ISTeP, Paris, France

$14{ }^{6}$ Office National des Forêts, R\&D, Fontainebleau, France

15

$16 *$ Corresponding author: Laure Soucémarianadin, souce@ geologie.ens.fr

17 Laboratoire de Géologie (UMR 8538) Ecole Normale Supérieure, 24 Rue Lhomond 75231

18 Paris CEDEX 5, France; phone: +331 4432 22 94; fax: +331 44322200

19

23 Type: Regular article 
24 Abstract

$25 \quad$ Aims

26 In temperate forests, soils contain a large part of the ecosystem carbon that can be partially

27 lost or gained upon global change. Our aim was to identify the factors controlling soil organic 28 carbon (SOC) stability in a wide part of French forests.

\section{Methods}

31 Using a set of soils from 53 French forest sites, we assessed the effects of depth (up to $1 \mathrm{~m}$ ),

32 soil class (dystric Cambisol; eutric Cambisol; entic Podzol), vegetation types (deciduous;

33 coniferous) and climate (continental influence; oceanic influence; mountainous influence) on 34 SOC stability using indicators derived from laboratory incubation, physical fractionation and 35 thermal analysis.

\section{Results}

Labile SOC pools decreased while stable SOC pool increased with depth. Soil class also significantly influenced SOC stability. Eutric Cambisols had less labile SOC in surface layers but had more labile SOC at depth $(>40 \mathrm{~cm})$ than the other soil classes. Vegetation influenced thermal indicators of SOC pools mainly in topsoils $(0-10 \mathrm{~cm})$. Mountainous climate forest soils had a low thermal SOC stability.

\section{Conclusions}

On top of the expected effect of depth, this study also illustrates the noticeable effect of soil class on SOC stability. It suggests that environmental variables should be included when mapping climate regulation soil service. 
50 Keywords: forest soils, particulate organic matter fractionation, pedology, Rock-Eval 6, soil

51 basal respiration, soil organic carbon persistence

Abbreviations: soil organic carbon (SOC), Rock-Eval 6 (RE6), particulate organic matter (POM), Oxygen index (OIRE6), Hydrogen index (HI), Hydrocarbons (HC)

\section{Introduction}

Forest ecosystems play a central role in the global carbon (C) cycle with their high potential

for atmospheric $\mathrm{CO}_{2}$ sequestration (Intergovernmental Panel on Climate Change 2000; Smith et al. 2014). About half of the terrestrial C sink is indeed located in forests (Canadell et al. 2007) and forest soils in particular store around 398 Pg C (Kindermann et al. 2008). The temperate biome holds a quarter of the world's forests (Tyrrell et al. 2012) and soils in temperate forests have twice as much carbon as the vegetation (Jarvis et al. 2005). Temperate forest soils have also constituted a C sink for over two decades (Pan et al. 2011; Tyrrell et al. 2012) with parts of the European — and particularly French (Jonard et al. 2017) —-forest soils being particularly efficient at sequestering C (e.g., Nabuurs et al., 2008). The contribution of deep soil to soil organic carbon (SOC) stocks has been previously highlighted (Jobbágy and Jackson 2000; Rumpel and Kögel-Knabner 2010), however there is still a lack of data on

69 deep/subsoil mineral (> $30 \mathrm{~cm}$ depth) SOC stocks (e.g., Tyrrell et al. 2012).

70 SOC is made up of very heterogeneous compounds (Amundson 2001; Trumbore 1997) with 71 turnover times ranging from a few days/weeks to several centuries and, for modelling 
purposes, can be roughly divided into active (labile), intermediate and passive (persistent) SOC kinetic pools.

Labile SOC is the most likely to be quickly affected by climate or land-use changes (Carter et al. 1998; Zhang et al. 2007), thus potentially contributing further to global warming.

Moreover, because of the central role of the SOC labile pool in short-to medium-term nutrient availability and soil structural stability (Wander 2004), its evolutions could have major effects on biomass (food/timber/etc.) production. Conversely when considering SOC long-term storage and possible sequestration, soils in which most of the total SOC is stable will perform better than soils with a greater proportion of their total SOC as labile SOC (Jandl et al. 2007; Lorenz and Lal 2010; Prescott 2010). It is thus essential to determine how much labile and persistent SOC are present in soils.

Despite being of such interest, there is still no standard technique to assess SOC stability but a set of complementary techniques are available. Respiration measurements and particulate organic matter (POM) quantification obtained by various methods of fractionation (density only / density + particle-size) (von Lützow et al. 2007) have been used for decades and are traditional metrics of SOC lability. Although the respired-C and POM-C fractions both represent a labile SOC pool, the former corresponds to a smaller SOC pool with a shorter mean residence time (usually $<1$ year for temperate in-situ conditions) (Feng et al. 2016) while the latter corresponds to a larger SOC pool with a longer mean residence time (usually < 20 year for temperate conditions (e.g., Balesdent 1996; Trumbore et al. 1996). This longer residence time may result from interactions with the soil structure; part of the POM-C fraction being occluded in micro-aggregates and protected from microbial respiration for longer time scales (Six et al. 2002). The mean residence time of the POM-C fraction can also exceed 20 years, especially in cold and mountainous areas (Leifeld et al. 2009) or in areas affected by wildfires where the POM-C fraction may contain large amounts of pyrogenic carbon with 
residence time in soils greater than the mean residence time of total SOC. Nevertheless, it has been shown that the POM-C fraction of temperate and mountainous soils of agroecosystems correspond roughly to the resistant material pools (RPM) of the RothC model (Zimmerman et al. 2007), which has a turnover rate of 3 years (Coleman and Jenkinson 1999). In this paper, the respired-C fraction will be referred to as the highly-labile SOC pool and the POM-C fraction will be termed labile SOC pool.

Thermal analysis techniques have also been used to characterize soil organic matter (SOM) stability (e.g., Plante et al. 2009). Among them, Rock-Eval 6 (RE6) analysis has shown promising results in the determination of SOM biogeochemical stability (Barré et al. 2016; Gregorich et al. 2015; Saenger et al. 2015; Sebag et al. 2016). RE6-derived parameters are reliable indicators of the stable SOC pool (Barré et al. 2016; Cécillon et al. 2018) and can be a useful complement to the aforementioned usual indicators of the labile SOC pool (Soucémarianadin et al. 2018). Specifically, one RE6-derived parameter, T50_HC_PYR, which corresponds to the temperature at which $50 \%$ of the hydrocarbons released as pyrolysis effluents during SOM pyrolysis have evolved, was linked to the highly-labile and the labile SOC pools (Gregorich et al. 2015; Soucémarianadin et al., 2018). In French forest soils, T50_HC_PYR was shown to be strongly and negatively correlated to the POM-C fraction but not to the respired-C fraction (Soucémarianadin et al. 2018). T50_HC_PYR could thus be used as an indicator of the labile SOC pool defined above, similarly to the POM-C fraction. Another RE6-derived parameter, the temperature at which $50 \%$ of the $\mathrm{CO}_{2}$ resulting from $\mathrm{SOM}$ thermal oxidation has evolved ( $\left.\mathrm{T}_{50} \mathrm{CO}_{2} \mathrm{O} \mathrm{O}\right)$ was positively related to an increasing proportion of persistent SOC (Barré et al. 2016; Cécillon et al. 2018) and to a POM-C depletion in temperate forest soils (Soucémarianadin et al. 2018). T50_CO2_Ox could thus be used as an indicator of the stable SOC pool with mean residence times greater than several decades (> 50-100 years; Cécillon et al. 2018). 
122 Few studies have assessed the factors controlling SOC stability over large areas. Several

123 recent studies have highlighted the importance of parent material and soil type on SOC

124 content and stability, SOC in deep soil layers being generally more stable compared to surface

125 SOC (Barré et al. 2017; Mason et al. 2016; Mathieu et al. 2015; Mulder et al. 2015). Camino-

126 Serrano et al. (2014) reported a larger highly labile SOC pool (based on concentrations of

127 dissolved organic carbon; DOC) in soils types characterized by a very acidic $\mathrm{pH}$ than in more

128 basic soils, especially in the subsoil layers below $20 \mathrm{~cm}$ depth. Considering croplands and

129 grasslands in Germany, Vos et al. (2017) showed that sandy soils had a larger labile SOC pool

130 (POM-C fraction) than soils with finer texture.

131 Land cover and vegetation type have also been shown to strongly control SOC stability.

132 Wiesmeier et al. (2014) found lower proportions of stable SOC pool in Bavarian forests

133 compared to grasslands or croplands, confirming results across Europe that showed that

134 afforestation of cropland and grassland generally decreased SOC stability (Poeplau and Don

135 2013). In the temperate forests of Bavaria, vegetation type was also shown to control SOC

136 stability, coniferous forests having higher labile SOC proportions than deciduous and mixed

137 forests (Wiesmeier et al. 2014). Similar results were obtained for the highly labile SOC pool

138 with lower dissolved organic carbon concentrations in broadleaved forests than coniferous

139 forests (Camino-Serrano et al. 2014). Variations of soil respiration were also observed at the

140 species level (e.g., three species of oaks; You et al. 2016).

141 Regarding climate, both global and more local studies have highlighted the strong positive

142 relationship with precipitation and the negative effect of temperature on SOC quantity

143 (Jobbágy and Jackson, 2000; Paul et al., 2002; Callesen et al., 2003; Wiesmeier et al. 2013).

144 Labile OM and particularly the POM-C fraction, has been shown to dominate in soils located

145 at higher elevations and experiencing colder mean annual temperatures (e.g., Leifeld et al.

146 2009; Sjögersten et al. 2011). Considering over 300 forested sites, higher DOC concentrations 
147 (highly labile SOC pool) were found in temperate sites than boreal and tropical sites (Camino-

148 Serrano et al. 2014). To the exception of the work of Wiesmeier et al. (2014), we are not

149 aware of large scale studies that would consider both the highly labile, labile and stable SOC

150 pools and devoted to forest soils, despite their large SOC stocks.

151 The objectives of the study were thus to assess the importance of various environmental

152 factors, soil depth, soil class, vegetation type and climate class in controlling the stability of

153 SOC in forest soils. To this purpose, we used a set of complementary techniques, namely the

154 Rock-Eval 6 thermal analysis, POM separation by size and density and a laboratory 10-week

155 incubation, and applied them to a large set of French forest soil samples that covers a large

156 pedoclimatic variability, a wide tree species diversity and includes deep samples (up to 1

157 meter).

158 We hypothesized that 1/ SOC stability would vary with depth with surface soil layers

159 containing more labile SOC while deep soil layers would contain more stable SOC; $2 /$

160 vegetation type would influence SOC stability mostly in surface soil layers (with higher rates

161 of C input from plants), SOC being more labile in topsoils of coniferous forests; 3 / soil class

162 would influence SOC stability mostly in medium/deep soil layers (below $20 \mathrm{~cm}$ ); and 4/

163 climate would influence SOC stability and SOC in mountainous plots would be more labile.

\section{Material and methods}

166 a. Sites and soil samples

167 We considered forest mineral soil samples from 53 permanent forest sites of the French

168 national network for the long term monitoring of forest ecosystems ("'RENECOFOR'),

169 established in 1992 (Ulrich 1995) by the National Forest Service (ONF;

170 http://www.onf.fr/renecofor) as a part of the European ICP-FORESTS (http://icp-forests.net/)

171 level 2 network (Fig. 1a). Our selected sites are variable in terms of climate (continental 
172 influence; oceanic influence; mountainous influence; with mean annual precipitation MAP

173 and mean annual temperature MAT ranging between $703-1894 \mathrm{~mm}$ and $4.8-12.3{ }^{\circ} \mathrm{C}$

174 respectively for the 1971-2000 period), soil type with a class constituted of soils related to

175 entic Podzols, another class constituted of eutric and epileptic Cambisols as well as Calcisols

176 and a last class constituted of dystric and hyperdystric Cambisols (IUSS Working Group

177 2015) and forest vegetation with coniferous [silver fir (Abies alba Mill.); Norway spruce

178 (Picea abies (L.) H. Karst.); European larch (Larix decidua Mill.); Scots pine (Pinus

179 sylvestris L.)] and deciduous [beech (Fagus sylvatica L.); sessile (Quercus petraea (Matt.)

180 Liebl.) and/or pedunculate oaks (Quercus robur L.)] stands. Stands are even-aged.

181 At each site, samples representing five soil layers were obtained $(0-10 \mathrm{~cm}, 10-20 \mathrm{~cm}, 20-40$

$182 \mathrm{~cm}, 40-80 \mathrm{~cm}$ and $80-100 \mathrm{~cm}$; Fig. 1b). Samples of the first three top soil layers were

183 collected, at each depth, as 5 (replicates; pooled together on site) $\times 5$ (sub-plots) sampling

184 points over the $5000 \mathrm{~m}^{2}$ central plot, by progressively digging a $50 \mathrm{~cm}$ wide soil profile

185 (Jonard et al. 2017; Ponette et al. 1997). This sampling campaign took place between 2007

186 and 2012. Samples of the two deeper soil layers were taken from two soil pits located just

187 outside the central plot and collected in 1994-1995 (Brêthes et al. 1997).

188 Bulk soils were air-dried and stored in plastic buckets right after sampling. One liter of soil of

189 each layer was retrieved for this study by isovolumetrically pooling the samples of the 5

190 subplots $(200 \mathrm{~mL}$ each) for the first three layers $(0-40 \mathrm{~cm})$ and the 2 faces of the 2 soil pits

191 (250 mL each) for the two deepest layers $(40-100 \mathrm{~cm})$. The pooled samples were sieved at 2

192 mm before analysis.

193

194 b. Elemental analysis

195 Bulk < 2 mm-sieved soil samples were ground (<250 $\mu$ m; ultra-centrifugal mill ZM 200,

196 Retsch Gmbh) and organic carbon and total nitrogen concentrations were determined by dry 
combustion with an elemental analyzer (CHN NA 1500, Carlo Elba). Samples with carbonates (total $\mathrm{CaCO}_{3}=3.5-835 \mathrm{~g} \cdot \mathrm{kg}^{-1}$ ) were first decarbonated following the same protocol as Harris et al. (2001). Briefly, $30 \mathrm{mg}$ of ground samples were weighed in $5 \mathrm{~mm} \times 9$ $\mathrm{mm}$ silver boats followed by the addition of $50 \mu \mathrm{L}$ of distilled water. The boats were put in a glass bell jar, next to a beaker containing $100 \mathrm{~mL}$ of concentrated $\mathrm{HCl}\left(12 \mathrm{~mol} \cdot \mathrm{L}^{-1}\right)$. The air in the jar was evacuated and samples let to sit in this HCl-saturated atmosphere to allow the acid to dissolve water and hydrolyze the carbonates for $8 \mathrm{~h}$. Then, the decarbonated samples were dried at $60{ }^{\circ} \mathrm{C}$ in the silver boats for at least $48 \mathrm{~h}$. Silver boats were further placed in 10 $\mathrm{mm} \times 10 \mathrm{~mm}$ tin boats and analyzed for $\mathrm{C}$ and $\mathrm{N}$.

POM fractions (see subsection d) were ground with a ball mill (mixer mill MM 200, Retsch Gmbh) or a mortar and pestle when the sample mass was less than $0.05 \mathrm{~g}$. Carbon concentration was determined as for the bulk soil.

\section{c. Respiration test}

For each sample, $20 \mathrm{~g}$ of $2 \mathrm{~mm}$-sieved soil were transferred in a $120 \mathrm{~mL}$ glass-flask and rehumected at pF $2.5(-0.033 \mathrm{MPa})$, which had been previously determined using a $5 \mathrm{Bar}$ pressure plate extractor (\#1600, Soilmoisture Equipment Corp.). The flasks were fitted with aluminum seals with PTFE-faced silicone septa to allow for headspace gas sampling and placed inside an incubator (AE240 BIO EXPERT, Froilabo SAS) kept at $20{ }^{\circ} \mathrm{C}$ for 10 weeks following a two-week period pre-incubation to allow the samples microbial activity to stabilize (data not included).

Headspace gases were sampled at 1 to 2 -week intervals during the 10 -week incubation period and $\mathrm{CO}_{2}$ concentrations were determined using an Agilent 490 micro-gas chromatograph equipped with the OpenLAB Chromatography Data System EZChrom software. 
221 When $\mathrm{CO}_{2}$ concentrations had reached 2.5-3\% or was expecting to do so before the next

222 measurement, and/or when the cap had been pierced with the needle four times, flasks were

223 opened and flushed with fresh and moist air to return $\mathrm{CO}_{2}$ concentrations to ambient levels to

224 avoid anoxia (while maintaining the moisture content), before returning them to the incubator.

225 The $\mathrm{CO}_{2}$ released during the incubation experiment was expressed as the cumulated soil

226 microbial respiration rate (basal respiration) from the initial SOC content over the 10-week

227 period, or the 10-week mineralizable SOC (respired-C) and reported as a percentage of total

228 SOC to account for differences in the $\mathrm{C}$ content of the various layers and sites. Respired-C

229 was used as indicator of the highly labile SOC pool with mean residence time below 1 year.

d. Particle size and density SOC fractionation

232 To isolate the particulate organic matter (POM) fraction, samples were first dried at $50{ }^{\circ} \mathrm{C}$ for

$23324 \mathrm{~h}$ before weighing $25 \mathrm{~g}$ and transferred them in polyethylene (PE) $250 \mathrm{~mL}$ flasks. We then

234 added $180 \mathrm{~mL}$ of $0.5 \%$ sodium hexametaphostate solution and ten $5 \mathrm{~mm}$-diameter glass beads

235 before shaking the samples overnight (50 rpm; $16 \mathrm{~h}$ ) on an overhead shaker (Reax 2,

236 Heidolph). Samples were thoroughly rinsed over a 50- $\mu \mathrm{m}$ mesh with deionized water. The

237 sand fraction was then transferred back to a dry PE flask with a sodium polytungstate (SPT)

238 solution of density $=1.6 \pm 0.03 \mathrm{~g} \cdot \mathrm{cm}^{-3}$ (Crow et al. 2007; Golchin et al. 1994) and solution

239 was added up to around $180 \mathrm{~mL}$. The flasks were shaken overhead by hand 10 times and

240 samples were left overnight to settle down after the cap of the flask was rinsed with the SPT

241 solution. The floating material was collected with a spatula and placed over a $50-\mu \mathrm{m}$ mesh

242 sieve. If necessary some SPT solution was added back to the flask and the previous step was

243 repeated. This time, samples were placed in a centrifuge for 30 minutes to accelerate the

244 separation (2750 rpm or $1250 \mathrm{~g}$ ). The floating material was again collected with the spatula or 245 pipetted depending on the amount left. This step was repeated if the light fraction was 
abundant. If not, samples were left to settle down overnight before one last collection. The

247 POM fraction on the sieve was thoroughly rinsed with deionized water throughout the whole

248 process. The sieves and fractions were then placed in the oven at $50{ }^{\circ} \mathrm{C}$ for $24 \mathrm{~h}$ before being

249 weighed. To account for differences in the $\mathrm{C}$ content of the different samples, we calculated

250 the proportion of OC in the POM fraction (POM-C), expressed as a percentage of total SOC.

251 POM-C was used as indicator of the labile SOC pool with mean residence time generally up

252 to 20 years.

e. Thermal analysis: Rock-Eval 6

255 The thermal analysis of the samples was performed with a Rock-Eval 6 turbo device (Vinci

256 Technologies, France). Details about the equipment have been previously published (Behar et

257 al. 2001). We adapted the procedure developed for the analysis of SOM by Disnar et al.

258 (2003). Briefly, about $60 \mathrm{mg}$ of ground sample were exposed to two consecutive thermal

259 treatments, first in a pyrolysis oven $\left(200-650^{\circ} \mathrm{C}\right.$; thermal ramping rate of $30^{\circ} \mathrm{C} \cdot \mathrm{min}^{-1}$; under

$260 \mathrm{~N}_{2}$ atmosphere) then in a combustion oven $\left(300-850^{\circ} \mathrm{C}\right.$; thermal ramping rate of

$26120{ }^{\circ} \mathrm{C} \cdot \mathrm{min}^{-1}$; under laboratory air atmosphere). At the beginning of the pyrolysis, there was an

262 isothermal step (at $200{ }^{\circ} \mathrm{C}$ ) during $\approx 200$ seconds during which the free hydrocarbons (HC)

263 were thermovaporized (S1 peak). The pyrolysis effluents (mostly HC) were detected and

264 quantified with flame ionization detection, while $\mathrm{CO}$ and $\mathrm{CO}_{2}$ were quantified by infrared

265 detection during both the pyrolysis and oxidation stages (Online Resource 1).

266 Two standard RE6 parameters describing SOC bulk chemistry were determined: the hydrogen

267 and oxygen indices ( $\mathrm{HI}$ and $\mathrm{OI}_{\mathrm{RE} 6}$ ). The $\mathrm{HI}$ index corresponds to the amount of hydrocarbons

268 formed during thermal pyrolysis of the sample (HC evolved between 200 and $650{ }^{\circ} \mathrm{C}$ minus

269 the S1 peak) divided by the total SOC content of the sample and is expressed in $\mathrm{mg} \mathrm{HC} \cdot \mathrm{g}^{-1}$

270 SOC. It describes the relative enrichment/depletion of SOC in hydrogen-rich moieties. The 
$271 \mathrm{OI}_{\text {RE6 }}$ index describes the relative oxidation status of SOC. It was calculated using the

272 equation proposed by Lafargue et al. (1998):

273

$\mathrm{OI}_{\mathrm{RE} 6}=16 / 28 \times \mathrm{OI}_{\mathrm{CO}}+32 / 44 \times \mathrm{OI}_{\mathrm{CO} 2}$

(equation 3)

Where $\mathrm{OI}_{\mathrm{CO} 2}$ corresponds to the $\mathrm{CO}_{2}$ yielded during thermal pyrolysis of the sample between 200 and $400{ }^{\circ} \mathrm{C}$ divided by the total SOC of the sample and $\mathrm{OI}_{\mathrm{CO}}$ corresponds to the $\mathrm{CO}$ yielded during thermal pyrolysis between 200 and $400-650{ }^{\circ} \mathrm{C}$ (wherever a minimum of $\mathrm{CO}$ production is observed; in the absence of a minimum, the default upper-limit temperature is set at $550{ }^{\circ} \mathrm{C}$ ) divided by the total SOC of the sample. Thus $\mathrm{OI}_{\mathrm{RE} 6}$ is expressed in $\mathrm{mg} \mathrm{O}_{2} \cdot \mathrm{g}^{-1}$ SOC.

We derived two additional RE6 parameter describing the thermal stability of SOC: (i) T50_HC_PYR, the temperature at which $50 \%$ of the HC resulting from the SOM pyrolysis had evolved and (ii) $\mathrm{T}_{50} \mathrm{CO}_{2} \mathrm{OX}$, the temperature at which $50 \%$ of the $\mathrm{CO}_{2}$ resulting from the $\mathrm{SOM}$ oxidation had evolved. The upper limit temperature for the integration of this signal was set at $611{ }^{\circ} \mathrm{C}$ to obtain a total $\mathrm{CO}_{2}$ signal evolved from pure $\mathrm{OM}$ without interference of carbonates. T50_HC_PYR was used as an indicator of the labile SOC pool with mean residence time generally up to 20 years (negative correlation with the labile SOC pool according to Gregorich et al. (2015) and Soucémarianadin et al. (2018)), while T50_CO2_Ox was used as an indicator of the stable SOC pool with mean residence time typically greater than 50-100 years, following Barré et al. (2016) and Cécillon et al. (2018). Signal processing of the RE6 thermograms, i.e., signal integration and calculation of $\mathrm{T}_{50 \_\mathrm{HC} \_\mathrm{PYR}}$ and $\mathrm{T}_{50 \_\mathrm{CO} 2 \mathrm{OX}}$, was performed with the R environment software v.3.3 (R Core Team 2016) using the hyperSpec (Beleites and Sergo 2015) and pracma (Borchers 2015) R packages. 
f. Calculations and statistical analyses

295 For the respiration test, samples with very low $\mathrm{C}$ content $(<0.2 \%)$ were not considered as the 296 C respired during the incubation period was too close to the limit of detection for reliable 297 determination. For the thermal analysis, we used a C content threshold of $0.1 \%$ and manually 298 inspected the pyrolysis thermograms for samples with $0.1 \% \leq \mathrm{C}$ content $\leq 0.25 \%$ to make 299 sure of the validity of the RE6 data (by assessing the shape of the signal). This resulted in the 300 selection of $\mathrm{n}=46 / 50$ and $\mathrm{n}=31 / 33$ samples for the soil layers $40-80 \mathrm{~cm}$ and $80-100 \mathrm{~cm}$ 301 and the two methods respectively, leading to a total $n=236$ for respiration test and $n=242$ 302 for RE6 (Fig. 1b). Because POM fractionation is time-consuming, we analyzed only the soil 303 layers $0-10 \mathrm{~cm}$ and $40-80 \mathrm{~cm}$ (Fig. 1b). At two sites, soil was too shallow $(<40 \mathrm{~cm})$ and no 304 sample was therefore collected for the $40-80 \mathrm{~cm}$ layer, and we used the same $\mathrm{C}$ threshold as 305 for the RE6 to select the POM samples, which lead to $n=103$. Out of the 236 samples 306 considered for the respiration test, 35 had a $\mathrm{CaCO}_{3}$ content over 5\% (5.2-82.0\%). We tested 307 the correlation between respired-C and $\mathrm{CaCO}_{3}$ content and, as it was not significant, decided 308 to proceed with the statistical analysis with all the samples.

309 Basic soil parameters ( $\mathrm{pH}$, texture, cation exchange capacity) were previously published in 310 Ponette et al. (1997). Average values are reported in Table 1 as well as the $\mathrm{C}$ content and C/N 311 ratio measured on the composite samples from this study. Because we used isovolumetric 312 pooled sampled, we saw appropriate to use average values of the 5 replicates $\times 5$ sub-plots.

313 This was confirmed by the results we obtained for the $\mathrm{C}$ content (Online Resource 2).

314 Relationships between the indicators of SOC stability and soil physico-chemical properties as 315 well as climatic data (MAT and MAP) were estimated using Spearman rank correlation as the 316 data did not meet the assumption of normality. Correlations were also performed on different 317 sets of samples for the different indicators (233 samples were included for the respiration test, 318242 for the RE6 comparison and 103 for the POM fractionation). 
A principal component of analysis (PCA) was performed to illustrate linear relations between

320 the indicators derived from the 3 methods at two different depths: $0-10 \mathrm{~cm}$ and $40-80 \mathrm{~cm}$.

321 For that purpose, data were log-transformed, centred and scaled. To determine the number of

322 principal components to select, we looked at the percentage of the total variance explained

323 and used a scree plot and Kaiser's criterion. We projected the physico-chemical and climatic

324 variables on the circle of correlations to see if any of those was associated with either of the

325 principal components and could thus be associated with SOC stability.

326 The statistical analysis to determine the driving factors of SOC stability was performed in two

327 steps: first over the complete soil profile and then on each soil layer individually. We used

328 multivariate models to assess the effects of the different environmental factors on the RE6-

329 based parameters and respiration test and POM fractionation results. For this "analysis by soil

330 profile", we used linear mixed models introducing a random intercept for each site $(\approx$ to treat

331 "site" as random effect) to take into account that the different layers constituted repeated

332 measures (increasing depth within a same RENECOFOR site). To do so we added the

333 compound symmetry structure, which is similar to the variance structure of random-intercept-

334 only model, to a generalized least squares function (that fits a linear model using generalized

335 least squares; (Pinheiro et al. 2016)). Model selection was then implemented with a top-down

336 strategy. The response variables were transformed, to the exception of T50_HC_PYR and

337 T50_CO2_ox, using the Box-Cox transformation technique ( $\log _{10}$ for POM-C and (respired-C +

338 1)), as they showed evidence of the variance increasing with the mean response. After

339 transformation, the residuals followed an approximate normal distribution.

340 To explore further the effects of soil classes, vegetation types and climatic zones within each

341 layer, we then conducted three-way analyses of variance (ANOVA) "by layer" with type II

342 analysis, when the interactions were not significant. Data were not transformed except for

343 respired-C. Multiple comparison tests were performed with Tukey's honest significant 
344 differences (to get adjusted $p$-values for all comparisons) and pairwise t-test (no adjustment

345 method). All comparisons were considered significant at an alpha value $(\alpha)$ of 0.05 .

346 All statistical analyses were performed using the R 3.3 statistical software (R Core Team

347 2016) with the factoextra (Kassambara and Mundt 2016), nlme (Pinheiro et al. 2016), lme4

348 (Bates et al. 2015) and car (Fox and Weisberg 2011) packages.

Results

a. Highly labile SOC pool: respired-C

Depth and soil class significantly influenced variations in soil basal respiration (respired-C) across our 53 study plots. The depth $\times$ soil interaction was also included in the selected model $(p=0.042$; Online Resource 3$)$. The respired-C fraction was on average $1.46 \pm 0.63 \%$ of total SOC (Online Resource 4) with no significant differences among vegetation types (Fig. 3) or climatic zones (Table 2). Respired-C decreased with depth (Fig. 2) but that factor was only marginally significant. Soil class was not significant in the $40-80 \mathrm{~cm}$ layer but otherwise entic

358 Podzols had significantly lower respired-C than the two other soil classes $(p=0.0010-0.042$; 359 Table 2; Fig. 4).

b. Labile SOC pool: POM-C and T50_HC_PYR

362 Only depth and soil type significantly affected variations in POM-C across our 53 study plots

363 (Online Resource 3). The labile SOC fraction contained in POM decreased by almost half

364 from the $0-10 \mathrm{~cm}$ layer to the $40-80 \mathrm{~cm}$ layer (with respective proportions of $22.6 \pm 7.3 \%$ and $36511.5 \pm 6.2 \%$ of total SOC; Fig. 2). The analysis by layer confirmed that neither climate nor 366 vegetation significantly influenced POM-C variations (Table 2; Fig. 3). Eutric Cambisols had 
significantly less POM-C than entic Podzols in the surface layer and dystric Cambisols at 4080 cm (Fig. 4; Online Resource 4).

Depth, vegetation type and soil class influenced variations in $\mathrm{T}_{50 \_H C}$ PYR, the RE6-derived temperature at which $50 \%$ of the $\mathrm{HC}$ resulting from the SOM pyrolysis had evolved. The three interactions depth $\times$ soil, depth $\times$ veg and soil $\times$ veg were also included in the selected model (Online Resource 3). T50_HC_PYR significantly increased with depth (422 \pm 8 to $452 \pm$ $13{ }^{\circ} \mathrm{C}$ at $0-10 \mathrm{~cm}$ and $80-100 \mathrm{~cm}$, respectively; Fig. 2), illustrating the decrease of the labile SOC pool with increasing depth. Eutric Cambisols had significantly higher T50_HC_PYR than dystric Cambisols and entic Podzols in the surface layer but had significantly lower T50_HC_PYR than the two other soil classes at 20-40 cm depth (Fig. 4; Online Resource 4). Moreover, in the surface layer, samples in deciduous plots had a significantly higher $\mathrm{T}_{50 \_H C \_P Y R}$ than those in coniferous plots $\left(427 \pm 9\right.$ and $417 \pm 7{ }^{\circ} \mathrm{C}$, respectively, $p<0.001$; Table 2; Fig. 3).

\section{c. Stable SOC pool: $\mathrm{T}_{50 \_} \mathrm{CO}_{2} \mathrm{OX}$}

Depth, vegetation and climate induced significant variations in the temperature at which $50 \%$ of the $\mathrm{CO}_{2}$ resulting from the SOM oxidation had evolved ( $\mathrm{T}_{50 \_C O 2}$ ox $)$ across our 53 study plots. The depth $\times$ climate interaction was also included in the selected model (Online Resource 3).

T50_CO2_ox increased with depth (from $399 \pm 9$ to $437 \pm 19{ }^{\circ} \mathrm{C}$ at $0-10 \mathrm{~cm}$ and $80-100 \mathrm{~cm}$, respectively; Fig. 2). Vegetation type was significant only in the top soil layers $(0-40 \mathrm{~cm})$ with samples from coniferous plots having a lower $\mathrm{T}_{50 \_C O 2}$ ox than those in deciduous plots (395 $\pm 6^{\circ} \mathrm{C}$ and $405 \pm 9^{\circ} \mathrm{C}$, respectively; Fig. 3). Soil class was a significant factor both in layers $0-10 \mathrm{~cm}(p=0.0085)$ and 40-80 cm $(p=0.0489$; Table 2$)$ but with contrasting trend: in the surface layer, eutric Cambisols had the highest $\mathrm{T}_{50 \_}$CO2_ox (significantly higher than 
entic Podzols) and the lowest $\mathrm{T}_{50}$ CO2_ox in the $40-80 \mathrm{~cm}$ layer (significantly lower than the 393 dystric Cambisols; Fig. 4; Online Resource 4). Climate was a significant factor in all layers: over the whole profile $(0-100 \mathrm{~cm}), \mathrm{T}_{50 \_} \mathrm{CO}_{-} \mathrm{OX}$ was lower in mountainous plots than in plots located in the two other climate classes ( $p \leq 0.0001-0.0159$; Table 2; Fig. 5).

d. Correlations between soil and climate characteristics and the indicators of SOC stability There were only a few significant and strong correlations between the indicators of SOC stability and soil physico-chemical properties (Table 3). Notably POM-C and T50_HC_PYR, the two indicators of the labile SOC pool, had strong and opposite correlations with HI ( $\rho=0.67$ and -0.67 respectively) and $\mathrm{OI}_{\mathrm{RE} 6}(\rho=-0.76$ and 0.63 respectively). POM-C was also positively correlated with $\mathrm{C} / \mathrm{N}$ ratio $(\rho=0.61)$. $\mathrm{T}_{50 \_C O 2 \_o x}$ was negatively correlated to the $\mathrm{C}$ content ( $\rho=-0.72$; Table 3$)$. Respired-C showed no strong correlation with soil or climate characteristics. In our samples we observed no strong correlation for the four indicators of SOC stability with soil texture, $\mathrm{pH}$ (although $\rho=-0.54$ with POM-C) or the climatic characteristics (MAT or MAP; Table 3).

407 Because of the strong "depth effect" on each indicator of SOC stability, we explored the evolution of these correlations within each soil layer and noticed that they also evolved with depth (Online Resource 5). To describe the similarity or dissimilarity in the different indicators of SOC lability, we conducted a principal component analysis (PCA) at the two 411 depths for which POM-C was available $(0-10$ and $40-80 \mathrm{~cm})$. In the $0-10 \mathrm{~cm}$ layer, the first 412 two principal components (PC) explained almost $60 \%$ of the total variance (Fig. 6). PC1 413 clearly separated soil samples dominated by highly labile SOC pool from those dominated by 414 labile SOC pool associated with POM-C. Indeed, along PC1, POM-C and respired-C showed 415 moderate to strong negative and positive loadings respectively, while $\mathrm{T}_{50 \_} \mathrm{CO}_{2} \mathrm{Ox}$ had moderate 416 positive loadings (Fig. 6). T50_HC_PYR showed strong negative loadings along PC2, while it had 
very weak negative loadings along PC1. Results were quite different in the $40-80 \mathrm{~cm}$ layer, where the first two principal components (PC) explained approximately $63 \%$ of the total variance (Fig. 6). In these deeper samples, PC1 tightly grouped soil samples with high proportion of highly labile SOC pool (respired-C) and those with high proportion of labile SOC pool associated with POM-C with strong positive loadings for both indicators along PC1. T50_CO2_OX and $\mathrm{T}_{50 \_H C}$ PYR had both strong positive loadings along PC2, while they had very weak loadings along PC1.

SOC content was not related to any of the indicators of SOC stability in the surface layer, while it was moderately and negatively correlated with POM-C, respired-C and $\mathrm{T}_{50 \_C O 2 \_O x}$ in the deep layer (Fig. 6; Online Resource 5). In the surface layer, pH was associated with positive values on the first PC (high respired-C), while sand content and soil $\mathrm{C} / \mathrm{N}$ ratio were associated with negative values on the first PC (high POM-C; Fig. 6; Online Resource 5). HI and $\mathrm{OI}_{\text {RE6 }}$ were well correlated to the indicators of highly labile and labile SOC pools, specifically in the surface layer. Correlations of the physico-chemical variables with POM-C were slightly lower at depth (Online Resource 5), but below $20 \mathrm{~cm}$ depth, all these correlations with $\mathrm{T}_{50} \mathrm{HC}_{-} \mathrm{PYR}$ and respired-C (directly with the indicators or with the PCs) had greatly decreased or even disappeared (Online Resource 5). Conversely, $\mathrm{T}_{50 \_C O 2} \mathrm{OX}$ was not more than weakly correlated with the physico-chemical parameters over the whole profile but its positive correlation with MAT tended to be higher in deeper layers (Online Resource 5; Fig.6).

The PCA biplot displaying the samples based on their soil class (Fig. 6) showed a difference between eutric Cambisol and entic Podzol with the two first PCs in the surface layer (0-10 $\mathrm{cm}$ ): samples of eutric Cambisols had higher respired-C, lower POM-C and generally higher T50_HC_PYR and $\mathrm{T}_{50 \_C O 2}$ OX than those of entic Podzols. 
In the deep layer $(40-80 \mathrm{~cm})$, the two PCs separated samples of dystric Cambisols from

442 samples of eutric Cambisols. The former were mostly characterized by high respired-C and

443 POM-C values and high values of $\mathrm{T}_{50 \_H C}$ PYR and $\mathrm{T}_{50 \_C O 2}$ OX. The latter had either high values

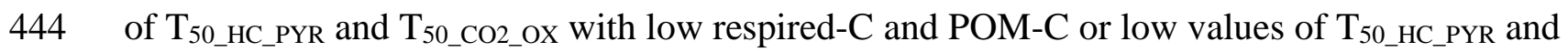

445 T50_CO2_Ox with high respired-C and POM-C. The second PC separated samples that had more

446 stable SOC (high values on PC2) from those that had less stable SOC (low values on PC2).

447 Dystric Cambisols thus appeared as having more stable SOC than the two other soil classes 448 (Fig. 6).

\section{Discussion}

451 a. Depth is the most discriminating factor of SOC stability

452 In our study sites, depth was the most discriminating factor, affecting significantly all

453 indicators of SOC stability. Indeed, with depth, we observed consistent trends for the

454 indicators of the highly-labile (decrease of respired-C) and the labile (decrease of POM-C and 455 increase of $\left.\mathrm{T}_{50 \_\mathrm{HC} \_\mathrm{PYR}}\right) \mathrm{SOC}$ pools, and an opposite trend for the indicator of the stable SOC 456 pool (increase of $\mathrm{T}_{50 \_C O 2 \_o x}$ ), verifying our first hypothesis.

457 Studies have shown a decrease in POM-C (\% of total SOC) with increasing depth down to 458 20-30 cm (Hassink 1995; Schrumpf and Kaiser 2015), down to $50 \mathrm{~cm}$ (Diochon and Kellman 459 2009) or down to $>140 \mathrm{~cm}$ (Cardinael et al. 2015; Moni et al. 2010). Previous studies have 460 also reported decreasing respired-C with depth during incubations of variable duration (e.g., 461 Dodla et al. 2012; Gillespie et al. 2014; Schrumpf et al. 2013; Wang and Zhong 2016 with 12 462 days at $22.5^{\circ} \mathrm{C}, 20$ days at $15{ }^{\circ} \mathrm{C}, 98$ days at $25^{\circ} \mathrm{C}, 60$ days at $25^{\circ} \mathrm{C}$, respectively).

463 Variations in soil basal respiration with depth have been related with variations in C dynamics 464 (e.g., Agnelli et al. 2004; Salomé et al. 2010; Wordell-Dietrich et al. 2017). 
Labile SOC content usually decreases while stable SOC increases with depth (e.g., Jenkinson et al. 2008; Lorenz and Lal 2005; Mathieu et al. 2015) and this is correlated with longer SOC turnover rates as exemplified by Torn et al. (1997) and Mathieu et al. (2015) who showed strong effects of depth on SOC mean age.
b. Soil class as a major factor controlling SOC stability

Soil class had significant effects on the indicators of the highly-labile (respired-C) and labile (POM-C and T $50 \_$HC_PYR $)$SOC pools. Contrary to our third hypothesis, these soil effects were not limited to the deeper layers and were indeed present in the surface layer for all four indicators of SOC stability (Table 2).

i) Modulation of the effect of depth by soil class

The effect of depth on SOC stability, i.e. the decrease of the labile SOC and concomitant increase in stable SOC was modulated by the soil class. First, the surface $(0-10 \mathrm{~cm})$ values of all SOC stability parameters varied among soil classes (Table 2; Fig. 4), surface layers of eutric Cambisols being generally enriched in stable SOC compared to other soil classes. This might be explained by a relative higher stabilization of SOC in the surface layer of the eutric Cambisols that could be due to a faster cycling in relation to lower $\mathrm{C} / \mathrm{N}$ ratios $(13.2 \pm 1.5 \mathrm{vs}$. $18.4 \pm 4.5$ for the other two classes $)$ and higher $\mathrm{pH}(6.2 \pm 0.9$ vs. $4.3 \pm 0.3$ for the other two classes), stimulating the mineralization of the more labile SOC and resulting in a more stable SOC overall. SOC stabilisation through Ca-mediated processes (occlusion, inclusion, sorption; Rowley et al., 2018) may also explain the higher SOC stability in surface layers of eutric Cambisols.

Then the amplitude of the evolution of SOC stability with depth varied among soil classes (Figure 4). Thus, the higher stability observed in the surface layer of eutric Cambisols had disappeared by $20-40 \mathrm{~cm}$ depth. This modulation of the effect of depth by soil class could be 
linked to different types of SOM moieties developed by very different pedogenetic processes,

491 eutric Cambisols showing a relatively more oxidized SOC than other soil classes (higher

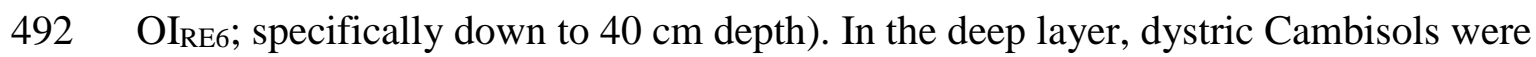

493 characterized by high OIRE6 values, which could be linked to larger stable SOC pools in this

494 soil class, likely associated with more oxidized SOC moieties (Cécillon et al., 2018).

495 Lastly, in our sites, soil class did not significantly affect the indicator of stable SOC

496 (T50_CO2_Ox; at least not for the whole profile model), and the stable SOC pool appeared

497 mostly driven by differences in MAT (specifically at depth; Fig 6; see section d. of the

498 Discussion). This result is seemingly contradictory to the findings of Mathieu et al. (2015)

499 who reported a strong influence of soil type on deep soil mean carbon age. It should be noted

500 that these authors covered a greater soil variability in their study and if we focus on the 3 soil

501 classes considered in our work, their results are similar to ours (i.e., no large difference among 502 the three soil classes).

ii) Soil variables explaining the pedological effect on SOC stability

504 Soil type is not often used as an explanatory factor of variations in SOC quality/stability (e.g., 505 Wiesmeier et al. 2014) and physico-chemical properties (e.g., clay content, pH, etc.) are often 506 preferred (e.g., Tian et al. 2016). We thus wondered whether a series of physico-chemical 507 parameters could have summarized the soil class effect on SOC stability.

508 The effect of soil type on the highly-labile and labile SOC pools may be due to differences in 509 soil texture (sand content), $\mathrm{pH}$ or $\mathrm{C} / \mathrm{N}$ ratio (Online Resource 6, Fig. 6). Indeed, a strong 510 effect of soil texture on SOC stability in the topsoil $(0-10 \mathrm{~cm})$ has previously been reported in 511 the literature. For instance, just like we did (POM-C in coarse-textured entic Podzols $=25.1 \pm$ $5127.6 \%$ vs. $19.2 \pm 5.6 \%$ in fine-textured eutric Cambisols; Fig. 4; Online Resource 4), several 513 studies have observed a trend of more labile SOC (expressed as POM-C or size of the 
514 intermediate SOC pool) in coarser soils (Schiedung et al. 2017; Wiesmeier et al. 2014) or

515 directly linked to the sand fraction (Tian et al. 2016; Vos et al. 2017).

516 In our sites, respired-C was higher in fine-textured soils up to $40 \mathrm{~cm}$ depth and was

517 significantly lower in Podzols. Conversely, several studies have reported higher C

518 mineralization rates in sandy soils than in finer-textured soils in various contexts from boreal

519 forests through croplands in Norway and all the way to Brazil (Bauhus et al. 1998; Frøseth

520 and Bleken 2015; Schmatz et al. 2017). These opposite results could originate from various

521 sources, and specifically differences in $\mathrm{C} / \mathrm{N}$ ratio. For our sites, the topsoil $\mathrm{C} / \mathrm{N}$ ratio in eutric

522 Cambisols was significantly lower $(13.3 \pm 1.5)$ than in entic Podzols (19.9 \pm 5 ; Online

523 Resource 4), which could affect the microbial use efficiency during the incubation (e.g.,

524 Cotrufo et al. 1995). Differences in pH could be another good explanation. Our entic Podzols

525 and eutric Cambisols had lower and higher $\mathrm{pH}$ than the till $(\approx$ sandy) and clay soils from the

526 Bauhus et al. (1998) study, respectively. It has been shown that a slight increase in $\mathrm{pH}$ could

527 significantly increase rates of mineralization (Curtin et al. 1998).

528 All these physico-chemical variables reflect the importance of SOM stoichiometry (C/N ratio)

529 (Ågren et al. 2013; Cleveland and Liptzin 2007) and substrate accessibility (reduced

530 protection via aggregation in sandy soils or increase in dissolved $\mathrm{OM}$ with higher $\mathrm{pH}$ ) for its

531 degradation (Dungait et al. 2012; Schmidt et al. 2011). However the lack of or low to

532 moderate correlations between the different indicators of SOC stability and these soil physico-

533 chemical parameters (texture and $\mathrm{pH}$ respectively; Table 3) suggest that there is not one

534 characteristics only responsible for the soil effect we observed or that, at least, they are not

535 valid at all depths of the soil profile as we have shown (Online Resource 5; Fig. 6). There are

536 likely complex interactions, reflecting pedogenetic processes behind this and, in that regard,

537 the soil class is integrative and goes beyond simple soil physico-chemical characteristics, and

538 is thus capable of reflecting variations in SOC stability. 
540 c. Vegetation type mostly affects SOC stability in topsoils

541 In our study sites, the effect of vegetation type (coniferous forest $v s$. deciduous forest) on

542 SOC stability was concentrated on the surface layer $(0-10 \mathrm{~cm})$, thus validating part of our

543 second hypothesis. Vegetation type significantly influenced both thermal indicators of SOC

544 stability in surface soil layers while the classical indicators of the highly labile (respired-C)

545 and the labile (POM-C) SOC pools were not affected by vegetation.

546 Effects of vegetation on the labile SOC pool have been previously reported, but they were

547 mainly observed at the tree species level (Bauhus et al. 1998; Augusto et al. 2002; Hobbie et

548 al. 2007; Olsen and Van Miegroet 2010; Laganière et al. 2012; Vesterdal et al. 2012; You et

549 al. 2016). Conversely, previous studies have also reported a lack of difference in the highly

550 labile SOC pool (estimated by respired-C) of topsoils in deciduous and coniferous stands

551 (Fissore et al. 2008; Van Miegroet et al. 2005).

552 In our study sites, the surface layer $(0-10 \mathrm{~cm})$ of coniferous stands had more labile SOC

553 (lower T50_HC_PYR) but also less stable SOC (lower T50_CO2_OX) than in deciduous stands,

554 validating the second part of our second hypothesis. Similar findings were reported in

555 Bavarian forests, where deciduous and mixed stands showed smaller labile SOC and larger

556 stable SOC pools than coniferous stands (Wiesmeier et al. 2014).

557 Deciduous forests indeed tend to rely on a more rapid nutrient cycling between soil and plant

558 (Cole and Rapp 1981). Quideau et al. (2001) showed that oak-derived SOM has undergone

559 extensive oxidation compared with the litter, while SOM under coniferous vegetation became

560 enriched in recalcitrant alkyl C. The authors conclude that deciduous stands were

561 characterized by a high microbial activity and rapid nutrient release whereas the accumulated

562 SOM in coniferous forests had a low bioavailability. The higher $\mathrm{pH}$ values of the litter in

563 deciduous stands favour bioturbation and incorporation of OM in surface mineral soil,

564 whereas the more acidic coniferous litter accumulates in the organic layers (e.g., Wiesmeier et 
al. 2013). These results could also be explained by lower $\mathrm{C} / \mathrm{N}$ ratios in deciduous plots (e.g.,

566 Cools et al. 2014). C/N ratio in deciduous stands $(15.0 \pm 2.8)$ were indeed lower than in

567 topsoils under coniferous $(18.4 \pm 5.1)$ and closer to that of the microbial biomass. This

568 difference in $\mathrm{C} / \mathrm{N}$ ratios between the two vegetation types was more drastic when considering

569 the plant inputs (deciduous $=46.5 \pm 9.5$; coniferous $=60.9 \pm 16.8$; data not shown) and high

$570 \mathrm{C} / \mathrm{N}$ ratios in litter are often associated with low decomposition rates (Melillo et al. 1982;

571 Norby et al. 2001; Tian et al. 2016). This would result in a higher litter mineralization

572 potential in deciduous stands and because the highly labile/labile pool is utilized more readily

573 in these plots (higher litter $\mathrm{C}$ turnover), it would result in a smaller size of the labile pool in

574 deciduous stands and thus a higher T50_HC_PYR. Indeed, there was a negative and moderate

575 correlation between $\mathrm{T}_{50}{ }_{\text {HC_PYR }}$ and the inputs $\mathrm{C} / \mathrm{N}$ ratio, but only in the top layer (Online

576 Resource 5). In the long term, the low $\mathrm{C} / \mathrm{N}$ ratio of the deciduous litters could also explain the

577 higher $\mathrm{T}_{50 \_C O 2}$ Ox through higher SOC stabilization (Berg 2000). This highlights the

578 importance of the bulk chemistry of SOC inputs (Hobbie et al. 2007; You et al. 2016) for

579 SOC cycling. This difference in SOC stability (in the mineral soil) between the two

580 vegetation types has also been mentioned in the review by Augusto et al. (2015) and the

581 reasons of this difference identified as a future research need.

582 The limited effect of vegetation types in our study sites could be linked to species

583 heterogeneity within the two vegetation types and this might be an important limitation of this

584 work. We chose to consider vegetation types and not tree species to obtain a more balanced

585 design (29 plots in coniferous stands and 24 in deciduous stands; Fig. 1a) and our deciduous

586 stands included both beech and oak-dominated forests. Inter-species variations in terms of

587 their characteristics (e.g., aboveground litter composition; roots) and their effects on the soil

588 could explain, at least partially, the limited effects of the (broad) vegetation classes in this

589 study. Some studies have indeed reported an effect of tree species on both in-situ and 
laboratory soil respiration rates (measured over a year) (Hobbie et al. 2007; Vesterdal et al.

591 2012). In oak stands, the respiration rate was greater than in beech stands, but similar to those in spruce stands, illustrating that the deciduous/coniferous dichotomy might be masking some species effects, at least on the labile SOC pool, but quite likely also on the stable SOC pool.

\section{d. Climatic control of the stable SOC pool}

In our study, climate effects on SOC stability were concentrated on the stable SOC pool. Soils located in plots with mountainous climate had higher $\mathrm{C}$ content (data not shown) than those in 598 plots in regions with oceanic or continental influence. However this higher concentration was 599 not associated with climate effects on the labile SOC indicators. Nevertheless climate was a 600 strong driver of the stable SOC indicator, SOC being less stable (lower $\mathrm{T}_{50 \_}$CO2_ox) in 601 mountainous plots. Our last hypothesis (SOC in mountainous plots would be more labile) was 602 thus only partially verified.

603 In Bavarian forests (Wiesmeier et al. 2014), the passive SOC pool (roughly equivalent to our 604 stable SOC pool) was negatively related to MAP, which agrees with our results as the 605 mountainous plots were the wettest $(1323 \pm 297 \mathrm{~mm})$ and there were negative correlations 606 between MAP and T50_CO2_ox in almost all layers (Online Resource 5). However, unlike us, 607 Wiesmeier et al. (2014) also detected a strong climate effect on the labile SOC as the latter 608 was under the control of both temperature and precipitation, and the most labile SOC was 609 found in mountainous regions. Similarly, Meier and Leuschner (2010) reported more labile 610 SOC when temperature decreased and precipitation increased, while Leifeld et al. (2009) 611 reported more POM-C at higher elevation in grasslands. In our study sites, there were no 612 more than weak correlations between our labile SOC pools and MAT and MAP, even when 613 considering individual layers (Online Resource 5). Nevertheless, it should be noted that the 614 mean elevation of our mountainous plots was $1230 \mathrm{~m}( \pm 280 \mathrm{~m})$ while Leifeld et al. (2009) 
615 had 5 out of their 8 sites located at $\geq 1410$ m elevation. Finally, this "high elevation" effect on

616 the labile fraction, expressed as POM-C requires caution as, in mountainous regions, lower

617 MAT tend to reduce microbial activity thus favouring SOC accumulation (e.g., Tewksbury

618 and Van Miegroet 2007), even in tropical areas (Araujo et al. 2017). In cold environments, the

619 residence time of this "labile" (as very close to the litter inputs) SOC is much longer than in

620 more temperate climate (Leifeld et al. 2009). In that particular context, the relationship

621 between thermal stability and SOC residence time/turnover may also be questioned and

622 requires further study.

623 Another possible limitation of the present study is that vegetation and climate appeared to be

624 confounded factors in our design with coniferous plots being preferentially found in

625 mountainous regions: our coniferous plots had a mean elevation of $831 \mathrm{~m}( \pm 476 \mathrm{~m})$ while it

626 was $511 \mathrm{~m}( \pm 413 \mathrm{~m})$ in the deciduous plots. This had an incidence on the MAT especially

627 (Online Resource 6).

628

629

630 Conclusions

631 In this study, thanks to a large set of forest soil samples with contrasted SOC stability and the

632 use of several indicators, we were able to highlight the influence of four environmental factors

633 on SOC stability: depth, soil, vegetation and climate; with the degree of significance of these

634 factors (and their interactions) varying among the SOC pools.

635 Our results show that pedology is a discriminant factor of SOC stability, more than individual

636 soil physico-chemical attributes. Soil type constitutes an integrated parameter that might be an

637 efficient way to capture SOC turnover properties. Upon modification in land management that

638 would result in a decrease of $\mathrm{C}$ inputs to the soil, our results let suggest that the SOC of eutric 
639 Cambisols may be less sensitive than the one of dystric Cambisols but specifically of entic

640 Podzols that may be more prone to losses.

641 To conclude, soil class, vegetation type and climatic zone all had a significant influence on

642 SOC stability at various depths in our studied French forest soils and these environmental

643 factors should thus be included in models estimating the ecosystem service of climate

644 regulation.

645

646

647 Acknowledgements

648 This work was supported by the French Environment and Energy Management Agency

649 (ADEME) [APR REACCTIF, piCaSo project] and Campus France [PRESTIGE-2015-3-

650 0008]. We thank M. Bryant, S. Cecchini, J. Mériguet, F. Savignac, and L. Le Vagueresse for

651 their technical support.

652

653 References

654 Agnelli A, Ascher J, Corti G, Ceccherini MT, Nannipieri P, Pietramellara G (2004)

655 Distribution of microbial communities in a forest soil profile investigated by microbial

656 biomass, soil respiration and DGGE of total and extracellular DNA. Soil Biol Biochem. doi:

$657 \quad$ 10.1016/j.soilbio.2004.02.004

658 Ågren GI, Hyvönen R, Berglund SL, Hobbie SE (2013) Estimating the critical N:C from

659 litter decomposition data and its relation to soil organic matter stoichiometry. Soil Biol

660 Biochem. doi: 10.1016/j.soilbio.2013.09.010

661 Amundson R (2001) The Carbon Budget in Soils. Annu Rev Earth Planet Sci 29:535-562.

662 doi: 10.1146/annurev.earth.29.1.535 
Araujo MA, Zinn YL, Lal R (2017) Soil parent material, texture and oxide contents have

664 little effect on soil organic carbon retention in tropical highlands. Geoderma. doi:

665

666

667

668

669

670

671

672

673

674

675

676

677

678

679

680

681

682

683

684

685

686

687

10.1016/j.geoderma.2017.04.006

Augusto L, Ranger J, Binkley D, Rothe A (2002) Impact of several common tree species of European temperate forests on soil fertility. Ann For Sci 59:233-253

Augusto L, De Schrijver A, Vesterdal L, Smolander A, Prescott C, Ranger J (2015)

Influences of evergreen gymnosperm and deciduous angiosperm tree species on the functioning of temperate and boreal forests. Biol Rev 90:444-466. doi: 10.1111/brv.12119

Balesdent J (1996) The significance of organic separates to carbon dynamics and its modelling in some cultivated soils. Eur J Soil Sci 47:485-493. doi: 10.1111/j.13652389.1996.tb01848.x

Barré P, Durand H, Chenu C, Meunier P, Montagne D, Castel G, Billiou D, Soucémarianadin L, Cécillon L (2017) Geological control of soil organic carbon and nitrogen stocks at the landscape scale. Geoderma 285:50-56. doi: 10.1016/j.geoderma.2016.09.029

Barré P, Plante AF, Cécillon L, Lutfalla S, Baudin F, Christensen BT, Eglin T, Fernandez JM, Houot S, Kätterer T, Le Guillou C, Macdonald A, van Oort F, Chenu C (2016) The energetic and chemical signatures of persistent soil organic matter. Biogeochemistry 130:112. doi: $10.1007 / \mathrm{s} 10533-016-0246-0$

Bates D, Mächler M, Bolker B, Walker S (2015) Fitting Linear Mixed-Effects Models Using lme4. Journal of Statistical Software, Articles 67:1-48

Bauhus J, Paré D, Côté L (1998) Effects of tree species, stand age and soil type on soil microbial biomass and its activity in a southern boreal forest. Soil Biol Biochem. doi:

10.1016/S0038-0717(97)00213-7

Behar F, Beaumont V, Penteado DB (2001) Rock-Eval 6 Technology: Performances and Developments. Oil Gas Sci Technol 56:111-134. doi: 10.2516/ogst:2001013 
Beleites C, Sergo V (2015) hyperSpec: a package to handle hyperspectral data sets in R Berg B (2000) Litter decomposition and organic matter turnover in northern forest soils. For Ecol Manage 133:13-22. doi: 10.1016/S0378-1127(99)00294-7

Brêthes A, Ulrich E, Lanier M (1997) RENECOFOR : caractéristiques pédologiques des 102 peuplements du réseau : observations de 1994/95. Office national des forêts, Département 694 des recherches techniques, Fontainebleau, France

695 Camino-Serrano M, Gielen B, Luyssaert S, Ciais P, Vicca S, Guenet B, Vos BD, Cools N, 696 Ahrens B, Altaf Arain M, Borken W, Clarke N, Clarkson B, Cummins T, Don A, Pannatier 697 EG, Laudon H, Moore T, Nieminen TM, Nilsson MB, Peichl M, Schwendenmann L, Siemens 698 J, Janssens I (2014) Linking variability in soil solution dissolved organic carbon to climate, 699 soil type, and vegetation type. Glob Biogeochem Cycles 28:497-509. doi: $10.1002 / 2013 G B 004726$

701 Canadell JG, Le Quéré C, Raupach MR, Field CB, Buitenhuis ET, Ciais P, Conway TJ, 702 Gillett NP, Houghton RA, Marland G (2007) Contributions to accelerating atmospheric $\mathrm{CO}_{2}$ 703 growth from economic activity, carbon intensity, and efficiency of natural sinks. PNAS 104:18866-18870. doi: 10.1073/pnas.0702737104

705 Cardinael R, Chevallier T, Barthès BG, Saby NPA, Parent T, Dupraz C, Bernoux M, 706 Chenu C (2015) Impact of alley cropping agroforestry on stocks, forms and spatial 707 distribution of soil organic carbon - A case study in a Mediterranean context. Geoderma 708 259-260:288-299. doi: 10.1016/j.geoderma.2015.06.015

709 Carter MR, Gregorich EG, Angers DA, Donald RG, Bolinder MA (1998) Organic C and N 710 storage, and organic $\mathrm{C}$ fractions, in adjacent cultivated and forested soils of eastern Canada. 711 Soil Tillage Res. doi: 10.1016/S0167-1987(98)00114-7 

van Oort F, Plante AF, Savignac F, Soucémarianadin L, Barré P (2018) A model based on Rock-Eval thermal analysis to quantify the size of the centennially persistent organic carbon pool in temperate soils. Biogeosciences Discussions 2018:1-25. doi: 10.5194/bg-2018-15

Cleveland CC, Liptzin D (2007) C:N:P stoichiometry in soil: is there a "Redfield ratio" for 717 the microbial biomass?. Biogeochemistry 85:235-252. doi: 10.1007/s10533-007-9132-0 718 Cole DW, Rapp M (1981) Elemental cycling in forest ecosystems. In: Reichle DE (ed) 719 Dynamic Properties of Forest Ecosystems. Cambridge University Press, pp 341-409 720 Coleman K, Jenkinson D (1999) RothC-26.3. A Model for the Turn-over of Carbon in 721 Soils. Model Description and Windows Users Guide. IACR - Rothamsted, Harpenden. 722 Cools N, Vesterdal L, De Vos B, Vanguelova E, Hansen K (2014) Tree species is the 723 major factor explaining C:N ratios in European forest soils. Forest Ecol Manag. doi:

\section{$724 \quad$ 10.1016/j.foreco.2013.06.047}

725 Cotrufo FM, Ineson P, Roberts DJ (1995) Decomposition of birch leaf litters with varying 726 C-to-N ratios. Soil Biol Biochem. doi: 10.1016/0038-0717(95)00043-E "

727 Crow SE, Swanston CW, Lajtha K, Brooks JR, Keirstead H (2007) Density fractionation 728 of forest soils: methodological questions and interpretation of incubation results and turnover 729 time in an ecosystem context. Biogeochemistry 85:69-90. doi: 10.1007/s10533-007-9100-8

730 Curtin D, Campbell CA, Jalil A (1998) Effects of acidity on mineralization: pH731 dependence of organic matter mineralization in weakly acidic soils. Soil Biol Biochem. doi: $732 \quad 10.1016 / \mathrm{S} 0038-0717(97) 00094-1$

733 Diochon AC, Kellman L (2009) Physical fractionation of soil organic matter:

734 Destabilization of deep soil carbon following harvesting of a temperate coniferous forest. J 735 Geophys Res 114. doi: 10.1029/2008JG000844 

(SOM) characterization by Rock-Eval pyrolysis: scope and limitations. Org Geochem 34:327343. doi: 10.1016/S0146-6380(02)00239-5

Dodla SK, Wang JJ, DeLaune RD (2012) Characterization of labile organic carbon in coastal wetland soils of the Mississippi River deltaic plain: Relationships to carbon functionalities. Sci Total Environ 435-436:151-158. doi: 10.1016/j.scitotenv.2012.06.090 turnover is governed by accessibility not recalcitrance. Glob Change Biol 18:1781-1796. doi: $10.1111 / \mathrm{j} .1365-2486.2012 .02665 . \mathrm{x}$

Feng W, Shi Z, Jiang J, Xia J, Liang J, Zhou J, Luo Y (2016) Methodological uncertainty 746 in estimating carbon turnover times of soil fractions. Soil Biol Biochem 100:118-124. doi: 10.1016/j.soilbio.2016.06.003

$$
\text { Fissore C, Giardina CP, Kolka RK, Trettin CC, King GM, Jurgensen MF, Barton CD, }
$$

McDowell SD (2008) Temperature and vegetation effects on soil organic carbon quality along a forested mean annual temperature gradient in North America. Global Change Biol 14:193205. doi: 10.1111/j.1365-2486.2007.01478.x

Fox J, Weisberg S (2011) An R Companion to Applied Regression decomposition rate of soil organic carbon and clover leaves, and related priming effect. Soil Biol Biochem. doi: 10.1016/j.soilbio.2014.10.004 C, Gregorich EG (2014) Perennially and annually frozen soil carbon differ in their susceptibility to decomposition: Analysis of Subarctic earth hummocks by bioassay, XANES and pyrolysis. Soil Biol Biochem 68:106-116. doi: 10.1016/j.soilbio.2013.09.021 
Golchin A, Oades JM, Skjemstad JO, Clarke P (1994) Study of free and occluded

761 particulate organic matter in soils by solid state ${ }^{13} \mathrm{C}$ CP/MAS NMR spectroscopy and scanning electron microscopy. Aust J Soil Res 32:285-309. doi: 10.1071/SR9940285

$$
\text { Gregorich EG, Gillespie AW, Beare MH, Curtin D, Sanei H, Yanni SF (2015) Evaluating }
$$

biodegradability of soil organic matter by its thermal stability and chemical composition. Soil Biol Biochem 91:182-191. doi: 10.1016/j.soilbio.2015.08.032

Harris D, Horwáth WR, van Kessel C (2001) Acid fumigation of soils to remove carbonates prior to total organic carbon or CARBON-13 isotopic analysis. Soil Sci Soc Am J 65:1853-1856. doi: 10.2136/sssaj2001.1853

Hassink J (1995) Density fractions of soil macroorganic matter and microbial biomass as predictors of C and N mineralization. Soil Biol Biochem 27:1099-1108. doi: 10.1016/00380717(95)00027-C

Hobbie SE, Ogdahl M, Chorover J, Chadwick OA, Oleksyn J, Zytkowiak R, Reich PB (2007) Tree species effects on soil organic matter dynamics: The role of soil cation composition. Ecosystems 10:999-1018. doi: 10.1007/s 10021-007-9073-4

Intergovernmental Panel on Climate Change (2000) Land Use, Land-Use Change and Forestry - A Special Report of the IPCC. Cambridge University Press, Cambridge, UK IUSS Working Group (2015) World reference base for soil resources 2014 (update 2015), international soil classification system for naming soils and creating legends for soil maps.

\section{World Soil Resources Reports}

Jandl R, Lindner M, Vesterdal L, Bauwens B, Baritz R, Hagedorn F, Johnson DW, Minkkinen K, Byrne KA (2007) How strongly can forest management influence soil carbon sequestration?. Geoderma 137:253-268. doi: 10.1016/j.geoderma.2006.09.003 
Jarvis PG, Ibrom A, Linder S (2005) 'Carbon forestry': managing forests to conserve

carbon. In: Griffiths HG, Jarvis PG (eds) The Carbon Balance of Forest Biomes. Taylor \& Francis, pp 356-377

Jenkinson DS, Poulton PR, Bryant C (2008) The turnover of organic carbon in subsoils.

Part 1. Natural and bomb radiocarbon in soil profiles from the Rothamsted long-term field experiments. Eur J Soil Sci 59:391-399. doi: 10.1111/j.1365-2389.2008.01025.x Jobbágy EG, Jackson RB (2000) The vertical distribution of soil organic carbon and its relation to climate and vegetation. Ecol Appl 10:423-436. doi: 10.1890/10510761(2000)010[0423:TVDOSO]2.0.CO;2

Jonard M, Nicolas M, Coomes DA, Caignet I, Saenger A, Ponette Q (2017) Forest soils in France are sequestering substantial amounts of carbon. Sci Total Environ 574:616-628. doi: 10.1016/j.scitotenv.2016.09.028

Kassambara A, Mundt F (2016) factoextra: Extract and Visualize the Results of Multivariate Data Analyses

Kindermann G, McCallum I, Fritz S, Obersteiner M (2008) A global forest growing stock, biomass and carbon map based on FAO statistics. Silva Fenn 42. doi: 10.14214/sf.244 Lafargue E, Marquis F, Pillot D (1998) Rock-Eval 6 Applications in Hydrocarbon Exploration, Production, and Soil Contamination Studies. Oil Gas Sci Technol 53:421-437. doi: $10.2516 /$ ogst:1998036

Laganière J, Paré D, Bergeron Y, Chen HYH (2012) The effect of boreal forest composition on soil respiration is mediated through variations in soil temperature and $\mathrm{C}$ quality. Soil Biol Biochem. doi: 10.1016/j.soilbio.2012.04.024

Leifeld J, Zimmerman M, Fuhrer J, Conen F (2009) Storage and turnover of carbon in grassland soils along an elevation gradient in the Swiss Alps. Global Change Biol 15:668679. doi: 10.1111/j.1365-2486.2008.01782.x 
Lorenz K, Lal R (2005) The depth distribution of soil organic carbon in relation to land use and management and the potential of carbon sequestration in subsoil horizons. Adv Agron 88:35-66. doi: 10.1016/S0065-2113(05)88002-2

Mason JA, Jacobs PM, Gruley KE, Reyerson P, Hanson PR (2016) Parent material influence on soil response to vegetation change, Southeastern Minnesota, U.S.A. Geoderma 275:1-17. doi: 10.1016/j.geoderma.2016.04.004 more by soil type than by climate: a worldwide meta-analysis of radiocarbon profiles. Global

Meier IC, Leuschner C (2010) Variation of soil and biomass carbon pools in beech forests across a precipitation gradient. Global Change Biol 16:1035-1045. doi: 10.1111/j.13652486.2009.02074.x

Melillo JM, Aber JD, Muratore JF (1982) Nitrogen and lignin control of hardwood leaf

822 litter decomposition dynamics. Ecology 63:621-626. doi: 10.2307/1936780

Moni C, Rumpel C, Virto I, Chabbi A, Chenu C (2010) Relative importance of sorption

824 versus aggregation for organic matter storage in subsoil horizons of two contrasting soils. Eur J Soil Sci 61:958-969. doi: 10.1111/j.1365-2389.2010.01307.x

827 Understanding large-extent controls of soil organic carbon storage in relation to soil depth and

828 soil-landscape systems. Glob Biogeochem Cycles 29:1210-1229. doi:

10.1002/2015GB005178

830 Nabuurs GJ, Thürig E, Heidema N, Armolaitis K, Biber P, Cienciala E, Kaufmann E,

831 Mäkipää R, Nilsen P, Petritsch R, Pristova T, Rock J, Schelhaas MJ, Sievanen R, Somogyi Z, 
832 Vallet P (2008) Hotspots of the European forests carbon cycle. For Ecol Manag. doi:

$833 \quad$ 10.1016/j.foreco.2008.04.009

834 Norby RJ, Cotrufo MF, Ineson P, O’Neill EG, Canadell JG (2001) Elevated CO 2 , litter

835 chemistry, and decomposition: a synthesis. Oecologia 127:153-165. doi:

$836 \quad 10.1007 / \mathrm{s} 004420000615$

837 Olsen HR, Van Miegroet H (2010) Factors affecting carbon dioxide release from forest and 838 rangeland soils in Northern Utah. Soil Sci Soc Am J 74:282-291. doi: 10.2136/sssaj2009.0095

839 Pan Y, Birdsey RA, Fang J, Houghton RA, Kauppi PE, Kurz WA, Phillips OL, Shvidenko 840 AZ, Lewis SL, Canadell JG, Ciais P, Jackson RB, Pacala SW, McGuire AD, Piao S,

841 Rautiainen A, Sitch S, Hayes D (2011) A large and persistent carbon sink in the world's

842 forests. Science 333:988-993. doi: 10.1126/science.1201609

843 Pinheiro J, Bates D, DebRoy S, Sarkar D, Team RC (2016) nlme: Linear and Nonlinear 844 Mixed Effects Models

845 Plante AF, Fernández JM, Leifeld J (2009) Application of thermal analysis techniques in 846 soil science. Geoderma 153:1-10. doi: 10.1016/j.geoderma.2009.08.016

847 Poeplau C, Don A (2013) Sensitivity of soil organic carbon stocks and fractions to 848 different land-use changes across Europe. Geoderma. doi: 10.1016/j.geoderma.2012.08.003 849 Ponette Q, Ulrich E, Brêthes A, Bonneau M, Lanier M (1997) RENECOFOR - Chimie des 850 sols dans les 102 peuplements du réseau : campagne de mesures 1993-95. ONF, Département 851 des recherches techniques, Fontainebleau, France

852 Prescott CE (2010) Litter decomposition: what controls it and how can we alter it to 853 sequester more carbon in forest soils? Biogeochemistry 101:133-149. doi: 10.1007/s10533854 010-9439-0 
856 between forest vegetation type and soil organic matter composition. Geoderma. doi: $10.1016 / \mathrm{S} 0016-7061(01) 00055-6$

R Core Team (2016) R: A Language and Environment for Statistical Computing organic carbon. Biogeochemistry 137:27-49. doi: 10.1007/s10533-017-0410-1 understood component of terrestrial C cycle. Plant Soil 338:143-158. doi: 10.1007/s11104010-0391-5

Surveying the carbon pools of mountain soils: A comparison of physical fractionation and 866 Rock-Eval pyrolysis. Geoderma 241-242:279-288. doi: 10.1016/j.geoderma.2014.12.001 and in subsoil may be controlled by different regulatory mechanisms. Global Change Biol 16:416-426. doi: 10.1111/j.1365-2486.2009.01884.x

Schiedung M, Don A, Wordell-Dietrich P, Alcántara V, Kuner P, Guggenberger G (2017) Thermal oxidation does not fractionate soil organic carbon with differing biological stabilities. J Plant Nutr Soil Sci 180:18-26. doi: 10.1002/jpln.201600172 residue quality and soil type influence the priming effect but not the fate of crop residue $\mathrm{C}$.

875 Plant Soil 414:229-245. doi: 10.1007/s11104-016-3120-х

876 Schmidt MWI, Torn MS, Abiven S, Dittmar T, Guggenberger G, Janssens IA, Kleber M, 877 Kögel-Knabner I, Lehmann J, Manning DAC, Nannipieri P, Rasse DP, Weiner S, Trumbore 878 SE (2011) Persistence of soil organic matter as an ecosystem property. Nature 478:49-56. doi: $879 \quad 10.1038 /$ nature 10386 
881 Storage and stability of organic carbon in soils as related to depth, occlusion within

882

883

884

885

886

887

888

889

890

891

892

893

894

895

896

897

898

899

900

901

902

903

904 aggregates, and attachment to minerals. Biogeosciences 10:1675-1691. doi: 10.5194/bg-101675-2013

Schrumpf M, Kaiser K (2015) Large differences in estimates of soil organic carbon turnover in density fractions by using single and repeated radiocarbon inventories. Geoderma 239-240:168-178. doi: 10.1016/j.geoderma.2014.09.025

Sebag D, Verrecchia EP, Cécillon L, Adatte T, Albrecht R, Aubert M, Bureau F, Cailleau G, Copard Y, Decaens T, Disnar J-, Hetényi M, Nyilas T, Trombino L (2016) Dynamics of soil organic matter based on new Rock-Eval indices. Geoderma 284:185-203. doi:

10.1016/j.geoderma.2016.08.025

Six J, Conant RT, Paul EA, Paustian K (2002) Stabilization mechanisms of soil organic matter: Implications for C-saturation of soils. Plant Soil 241:155-176. doi:

10.1023/A:1016125726789

Sjögersten S, Alewell C, Cécillon L, Hagedorn F, Jandl R, Leifeld J, Martinsen V, Schindlbacher A, Sebastià M-, Van Miegroet H (2011) Mountain Soils in a Changing Climate? Vulnerability of Carbon Stocks and Ecosystem Feedbacks. In: Soil Carbon in Sensitive European Ecosystems. John Wiley \& Sons, Ltd, Chichester, UK, pp 118-148 Smith P, Bustamante M, Ahammad H, Clark H, Dong H, Elsiddig EA, Haberl H, Harper R, House J, Jafari M, Masera O, Mbow C, Ravindranath NH, Rice CW, Robledo Abad C, Romanovskaya A, Sperling F, Tubiello F (2014) Agriculture, Forestry and Other Land Use (AFOLU). In: Edenhofer O, Pichs-Madruga R, Sokona Y, Farahani E, Kadner S, Seyboth K, Adler A, Baum I, Brunner S, Eickemeier P, Kriemann B, Savolainen J, Schlömer S, von Stechow C, Zwickel T, Minx JC (eds) Climate Change 2014: Mitigation of Climate Change. Contribution of Working Group III to the Fifth Assessment Report of the Intergovernmental 
905 Panel on Climate Change. Cambridge University Press, Cambridge, UK and New York, NY,

906 USA, pp 811-922

907 Soucémarianadin LN, Cécillon L, Chenu C, Baudin F, Nicolas M, Girardin C, Barré P

908 (2018) Is Rock-Eval 6 thermal analysis a good indicator of soil organic carbon lability? - A

909 method-comparison study in forest soils. Soil Biol Biochem 117:108-116. doi:

$910 \quad 10.1016 / j . s o i l b i o .2017 .10 .025$

911 Tewksbury CE, Van Miegroet H (2007) Soil organic carbon dynamics along a climatic

912 gradient in a southern Appalachian spruce-fir forest. Can J For Res 37:1161-1172. doi:

$913 \quad 10.1139 / \mathrm{X} 06-317$

914 Tian Q, He H, Cheng W, Bai Z, Wang Y, Zhang X (2016) Factors controlling soil organic

915 carbon stability along a temperate forest altitudinal gradient. Sci Rep 6:18783. doi:

$916 \quad 10.1038 /$ srep18783

917 Torn MS, Trumbore SE, Chadwick OA, Vitousek PM, Hendricks DM (1997) Mineral

918 control of soil organic carbon storage and turnover. Nature 389:170-173. doi: 10.1038/38260

919 Trumbore SE (1997) Potential responses of soil organic carbon to global environmental

920 change. Proc Natl Acad Sci U S A 94:8284-8291

921 Trumbore SE, Chadwick OA, Amundson R (1996) Rapid exchange between soil carbon

922 and atmospheric carbon dioxide driven by temperature change. Science. doi:

$923 \quad 10.1126 /$ science. 272.5260 .393

924 Tyrrell ML, Ross J, Kelty M (2012) Carbon Dynamics in the Temperate Forest. In: Ashton

925 MS, Tyrrell ML, Spalding D, Gentry B (eds) Managing Forest Carbon in a Changing Climate.

926 Springer Netherlands, Dordrecht, pp 77-107

927 Ulrich E (1995) Le réseau RENECOFOR : objectifs et réalisation. Rev for fr 47:107-124.

928 doi: $10.4267 / 2042 / 26634$ 
930 carbon distribution and quality in a montane rangeland-forest mosaic in northern Utah. Forest 931 Ecol Manag. doi: 10.1016/j.foreco.2005.08.017 and rates of soil carbon turnover differ among six common European tree species. For Ecol

934 Manag 264:185-196. doi: 10.1016/j.foreco.2011.10.009

935 von Lützow M, Kögel-Knabner I, Ekschmitt K, Flessa H, Guggenberger G, Matzner E, 936 Marschner B (2007) SOM fractionation methods: Relevance to functional pools and to 937 stabilization mechanisms. Soil Biol Biochem 39:2183-2207. doi:

938 10.1016/j.soilbio.2007.03.007

939 Vos C, Jaconi A, Jacobs A, Don A (2017) Hot regions of labile and stable soil organic 940 carbon in Germany -- Spatial variability and driving factors. SOIL 2017:1-35. doi:

$941 \quad 10.5194 /$ soil-2017-30

942 Wander M (2004) Soil organic matter fractions and their relevance to soil function. In:

943 Magdoff F, Weil RR (eds) Soil Organic Matter in Sustainable Agriculture. CRC Press, pp 67944102

945 Wang Q, Zhong M (2016) Composition and mineralization of soil organic carbon pools in 946 four single-tree species forest soils. Journal of Forestry Research 27:1277-1285. doi:

$947 \quad 10.1007 / \mathrm{s} 11676-016-0244-\mathrm{Z}$

948 Wiesmeier M, Prietzel J, Barthold F, Spörlein P, Geuß U, Hangen E, Reischl A, Schilling 949 B, von Lützow M, Kögel-Knabner I (2013) Storage and drivers of organic carbon in forest 950 soils of southeast Germany (Bavaria) - Implications for carbon sequestration. For Ecol Manag 951 295:162-172. doi: 10.1016/j.foreco.2013.01.025

952 Wiesmeier M, Schad P, von Lützow M, Poeplau C, Spörlein P, Geuß U, Hangen E, Reischl 953 A, Schilling B, Kögel-Knabner I (2014) Quantification of functional soil organic carbon pools 
954 for major soil units and land uses in southeast Germany (Bavaria). Agric Ecosyst Environ. 955 doi: 10.1016/j.agee.2013.12.028

956 Wordell-Dietrich P, Don A, Helfrich M (2017) Controlling factors for the stability of 957 subsoil carbon in a Dystric Cambisol. Geoderma. doi: 10.1016/j.geoderma.2016.08.023 958 You Y, Wang J, Sun X, Tang Z, Zhou Z, Sun OJ (2016) Differential controls on soil 959 carbon density and mineralization among contrasting forest types in a temperate forest 960 ecosystem. Sci Rep 6:22411. doi: 10.1038/srep22411

961 Zhang J, Song C, Wenyan Y (2007) Tillage effects on soil carbon fractions in the Sanjiang 962 Plain, Northeast China. Soil Tillage Res. doi: 10.1016/j.still.2006.03.014

963 Zimmermann M, Leifeld J, Schmidt MWI, Smith P, Fuhrer J (2007) Measured soil organic 964 matter fractions can be related to pools in the RothC model. Eur J Soil Sci 58:658-667. doi: 965 10.1111/j.1365-2389.2006.00855.x 
968 Fig. 1 (a) Location of the 53 study sites from the French national network for the long term 969 monitoring of forest ecosystems (RENECOFOR) and their repartition among the climatic 970 zones and vegetation types and soil classes; (b) Number of samples by depths and analyses 971 performed to assess SOC stability

972

973 Fig. 2 Evolution of respired-C, POM-C, T50_HC_PYR and T50_CO2_Ox in the five soil layers of the 97453 RENECOFOR plots. The horizontal black lines show the medians. The bottom and top of 975 the box show the first and third quartiles, respectively. $\mathrm{n}=53$ for layers $0-10 \mathrm{~cm}, 10-20 \mathrm{~cm}$ 976 and 20-40 cm; $\mathrm{n}=50$ (RE6 and POM-C) or 46 (respired-C) for layer 40-80 cm; n = 33 (RE6) or 31 (respired-C) for layer $80-100 \mathrm{~cm}$. For each indicator, different letters indicate

978 significant differences between the means of the different layers

979

980 Fig. 3 Variations in the indicators of SOC stability respired-C and POM-C (top) and thermal

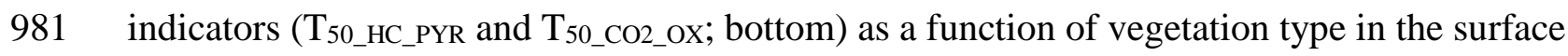
$982(0-10 \mathrm{~cm})$ layer. The horizontal black line shows the median for each vegetation type. The 983 bottom and top of the box show the first and third quartiles, respectively. $n=29$ and 24 for 984 coniferous and deciduous plots respectively. For each indicator, different letters indicate 985 significant differences between the means of the different layers 986

987 Fig. 4 Variations in indicators of SOC stability respired-C and POM-C (top) and thermal 988 indicators $\left(\mathrm{T}_{50 \_H C}\right.$ PYR and $\mathrm{T}_{50 \_C O 2}$ OX ; bottom) as a function of depth for all three soil classes. $989 \mathrm{n}=53$ for layers $0-10 \mathrm{~cm}, 10-20 \mathrm{~cm}$ and $20-40 \mathrm{~cm} ; \mathrm{n}=50($ RE6 and POM-C) or 46 990 (respired-C) for layer 40-80 cm; $\mathrm{n}=33$ (RE6) or 31 (respired-C) for layer $80-100 \mathrm{~cm}$ 991 
992 Fig. 5 Variations in the thermal indicator T $50 \_C 02$ Ox $($ stable SOC pool) in the three climatic 993 zones as a function of depth

994

995 Fig. 6 Principal components analysis (PCA) loadings plots (top) and biplots (bottom) of the 4 996 indicators of SOC stability (red arrows) along the first two principal component axes (PC1 997 and PC2) for two layers: (left) $0-10 \mathrm{~cm}(\mathrm{n}=53)$ and (right) $40-80 \mathrm{~cm}(\mathrm{n}=46)$. In the loading 998 plots, the physico-chemical parameters and climatic data (black arrows) were projected in the 999 circle of correlations for information. In the biplots, the samples were represented by their soil 1000 class and the $95 \%$ ellipses for the three soil classes were added 
Table 1 Mean (and standard deviation) of SOC content, C/N ratio of the bulk soil and RE6-derived bulk chemistry parameters (HI, OIRE6), as well as the averaged values derived from Ponette et al. (1997) and Jonard et al. (2017) for the texture, $\mathrm{pH}_{\text {water }}$ and the cationic exchange capacity, in the five soil layers for the 53 RENECOFOR plots

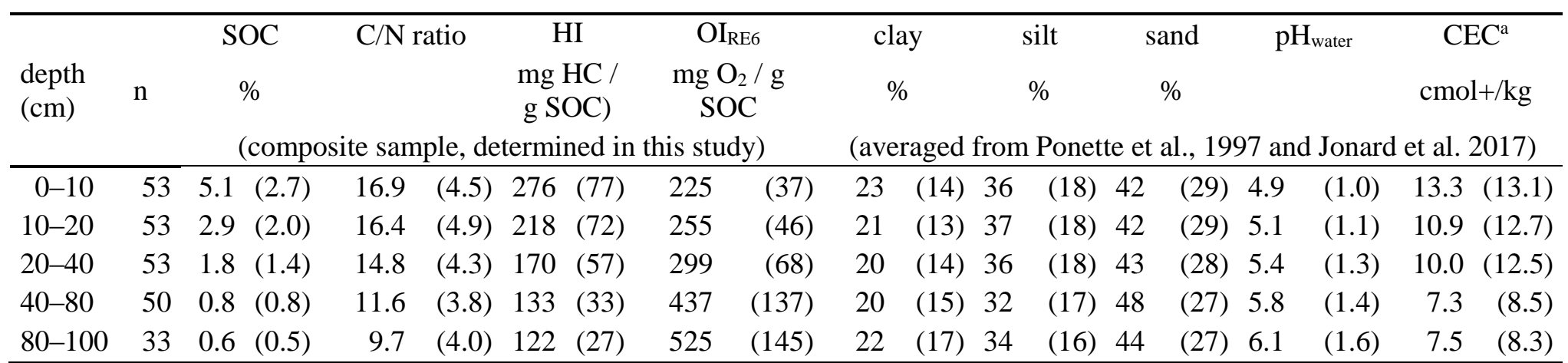

a determined by extraction of the exchangeable cations with barium chloride (ISO 11260:1994) 
Table 2 Results ( $p$-value) of the 3-way ANOVA (analysis by layer) with the factors soil class (soil), vegetation type (veg) and climatic zone (clim) and their interactions for each response variable obtained from respiration test (respired-C), POM fractionation (POM-C) and RE6 thermal analysis $\left(\mathrm{T}_{50}{ }_{\mathrm{HC}} \mathrm{PYR} ; \mathrm{T}_{50 \_\mathrm{CO}} \_\mathrm{OX}\right)$. If the response variable needed to be transformed to conform to the assumptions of ANOVA, the transformation that was used is specified.

Significance is indicated as follows: ***: $p<0.001$; **: $p<0.01 ; *: p<0.05 ; .: p<0.1$; NS $=$ not significant

Factor

Interaction

\begin{tabular}{|c|c|c|c|c|c|c|c|}
\hline $\begin{array}{c}\text { Respiration } \\
\text { depth }(\mathrm{cm})\end{array}$ & variable & soil & veg & clim & soil $\times$ veg & soil $\times$ clim & veg $\times$ clim \\
\hline $0-10$ & respired-C & $* *$ & NS & NS & NS & NS & NS \\
\hline $10-20$ & $\log _{10}($ respired-C +1$)$ & $* * *$ & NS & NS & NS & NS & NS \\
\hline $20-40$ & $\log _{10}($ respired-C +1$)$ & $* *$ & NS & NS & NS & NS & NS \\
\hline $40-80$ & $\log _{10}($ respired-C +1$)$ & NS & NS & NS & NS & NS & NS \\
\hline $80-100$ & $\log _{10}($ respired-C +1$)$ & $*$ & NS & NS & NS & NS & NS \\
\hline
\end{tabular}

\section{POM fractionation}

\begin{tabular}{cccccccc} 
depth $(\mathrm{cm})$ & variable & soil & veg & clim & soil $\times$ veg & soil $\times$ clim & veg $\times$ clim \\
\hline $0-10$ & POM-C & $*$ & NS & NS & NS & NS & NS \\
$40-80$ & POM-C & $*$ & NS & NS & NS & NS & NS \\
\hline
\end{tabular}

\begin{tabular}{|c|c|c|c|c|c|c|c|}
\hline \multicolumn{8}{|c|}{ Rock-Eval thermal analysis } \\
\hline depth $(\mathrm{cm})$ & variable & soil & veg & clim & soil $\times$ veg & soil $\times$ clim & veg $\times$ clim \\
\hline $0-10$ & $\mathrm{~T}_{50 \_ \text {HC_PYR }}$ & $* * *$ & $* * *$ & NS & NS & & NS \\
\hline $10-20$ & $\mathrm{~T}_{50 \text { _HC_PYR }}$ & NS & NS & NS & & NS & NS \\
\hline $20-40$ & $\mathrm{~T}_{50 \_ \text {HC_PYR }}$ & * & NS & NS & NS & NS & NS \\
\hline $40-80$ & $\mathrm{~T}_{50 \_ \text {HC_PYR }}$ & NS & NS & NS & NS & NS & NS \\
\hline $80-100$ & $\mathrm{~T}_{50 \_H C \_P Y R}$ & NS & NS & NS & NS & NS & NS \\
\hline $0-10$ & $\mathrm{~T}_{50 \_\mathrm{CO} 2 \_\mathrm{OX}}$ & $* *$ & $* * *$ & $* *$ & NS & NS & NS \\
\hline $10-20$ & $\mathrm{~T}_{50 \_\mathrm{CO} 2 \_\mathrm{OX}}$ & NS & $*$ & $* *$ & NS & $*$ & NS \\
\hline $20-40$ & $\mathrm{~T}_{50 \_\mathrm{CO} 2 \_\mathrm{OX}}$ & NS & $*$ & $* *$ & NS & $*$ & NS \\
\hline $40-80$ & $\mathrm{~T}_{50 \_\mathrm{CO} 2 \mathrm{OX}}$ & $*$ & NS & $* * *$ & NS & NS & NS \\
\hline $80-100$ & $\mathrm{~T}_{50 \_\mathrm{CO} 2 \_\mathrm{OX}}$ & NS & NS & $*$ & NS & NS & NS \\
\hline
\end{tabular}


Table 3 Spearman correlation coefficients between the RE6-derived temperature parameters ( $\mathrm{T}_{50 \_H C}$ _PYR and $\left.\mathrm{T}_{50 \_C O 2} \mathrm{OX}\right)$, the 10 -week mineralizable SOC (respired-C), the proportion of SOC in the POM fraction (POM-C) and the physico-chemical properties of the samples (C content; $\mathrm{C} / \mathrm{N}$ ratio; $\mathrm{HI}$; $\mathrm{OI}_{\mathrm{RE} 6}$; texture, clay and sand content; $\mathrm{pH}$; cationic exchange capacity, CEC) and climatic data of the plots (mean annual precipitation, MAP; mean annual temperature, MAT). Significance is indicated as follows: ***: $\mathrm{p}<0.001 ; * *$ : $\mathrm{p}<0.01$; $^{*} \mathrm{p}<$ 0.05. The high $(>0.6)$ correlations are marked in bold. $n=242$ for the RE6 parameters, $n=$ 236 for respired-C and $n=103$ for POM-C

\begin{tabular}{|c|c|c|c|c|}
\hline & T50_HC_PYR & $\mathrm{T}_{50 \_\mathrm{CO} 2 \_\mathrm{OX}}$ & respired-C & POM-C \\
\hline SOC & $-0.58 * * *$ & $-0.72 * * *$ & 0.03 & $0.52 * * *$ \\
\hline $\mathrm{C} / \mathrm{N}$ ratio & $-0.34 * * *$ & $-0.43 * * *$ & $-0.13^{*}$ & $0.61 * * *$ \\
\hline $\mathrm{HI}$ & $-0.67 * * *$ & $-0.53 * * *$ & 0.08 & $0.67 * * *$ \\
\hline $\mathrm{OI}_{\mathrm{RE} 6}$ & $0.63 * * *$ & $0.50 * * *$ & -0.04 & $-0.76 * * *$ \\
\hline Clay & -0.06 & -0.03 & $0.19 * *$ & -0.18 \\
\hline Sand & 0.02 & 0.10 & $-0.15^{*}$ & 0.18 \\
\hline $\mathrm{pH}_{\text {water }}$ & $0.31 * * *$ & $0.33 * * *$ & $0.23 * * *$ & $-0.54 * * *$ \\
\hline CEC & $-0.33 * * *$ & $-0.25 * * *$ & $0.31 * * *$ & 0.08 \\
\hline MAP & 0.06 & $-0.20 * *$ & $-0.16^{*}$ & -0.11 \\
\hline MAT & 0.01 & $0.19 * *$ & -0.09 & -0.02 \\
\hline
\end{tabular}




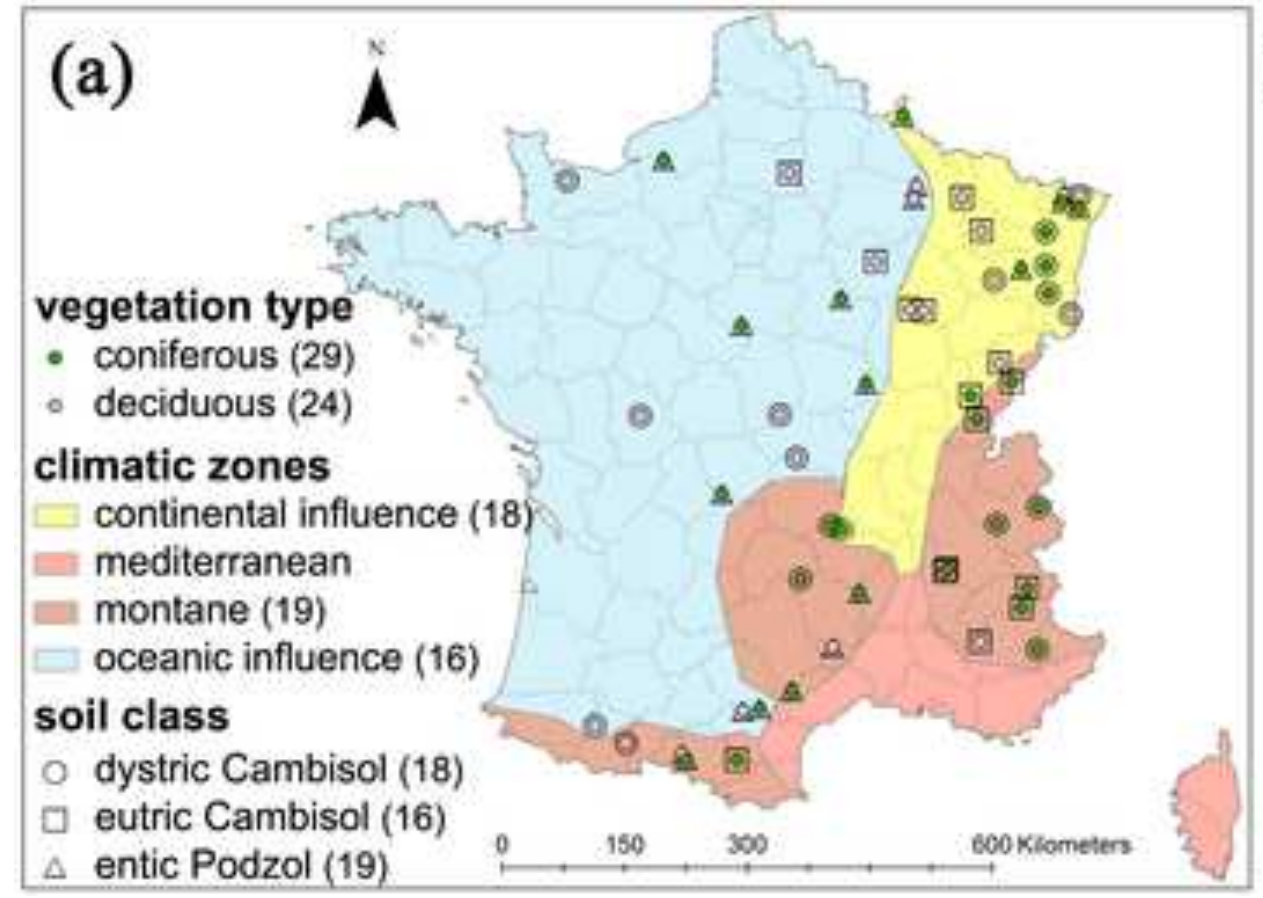

(b) Soil samples from the

Methods used to assess SOC stability

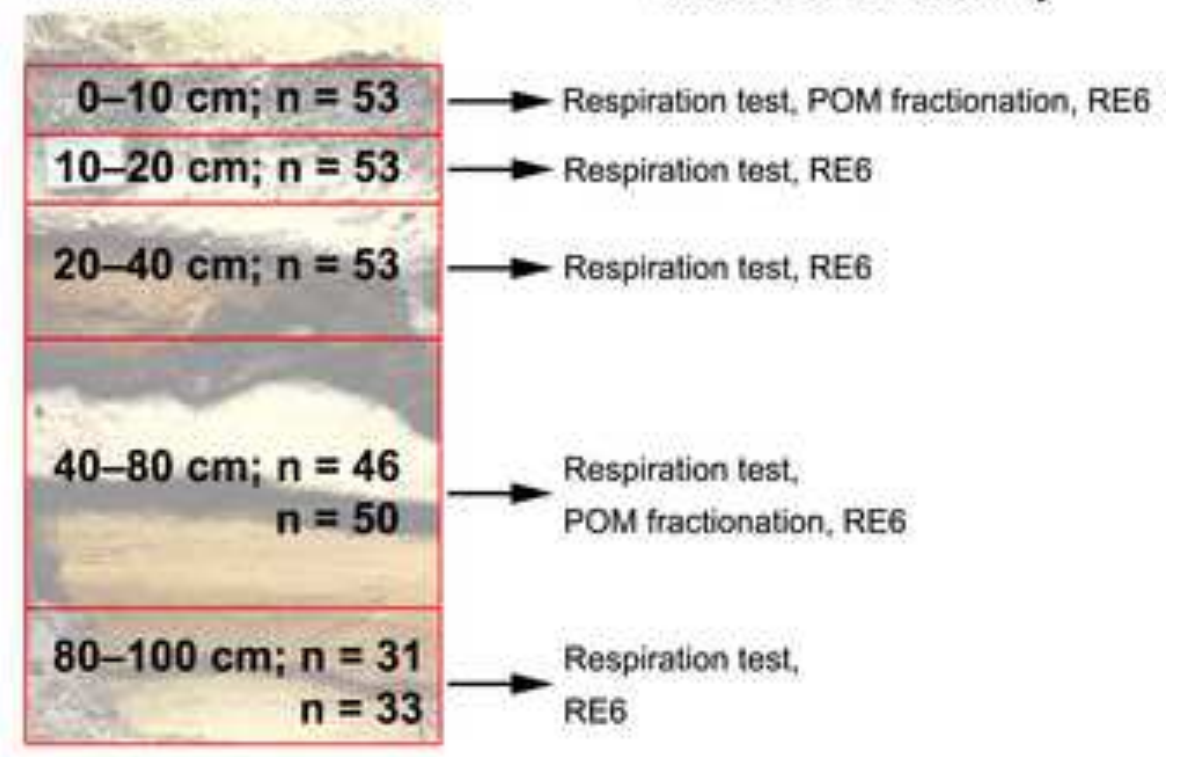



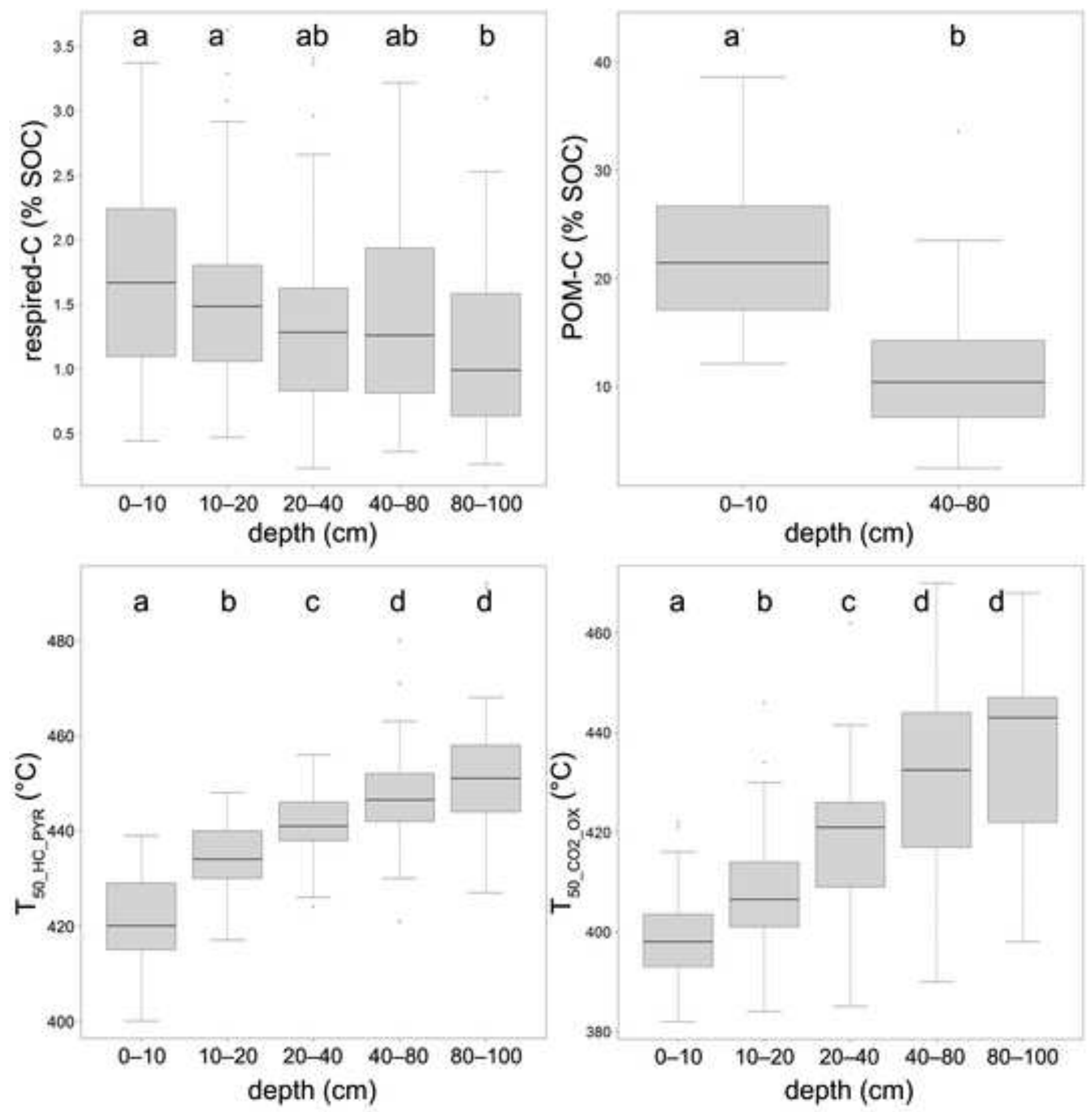

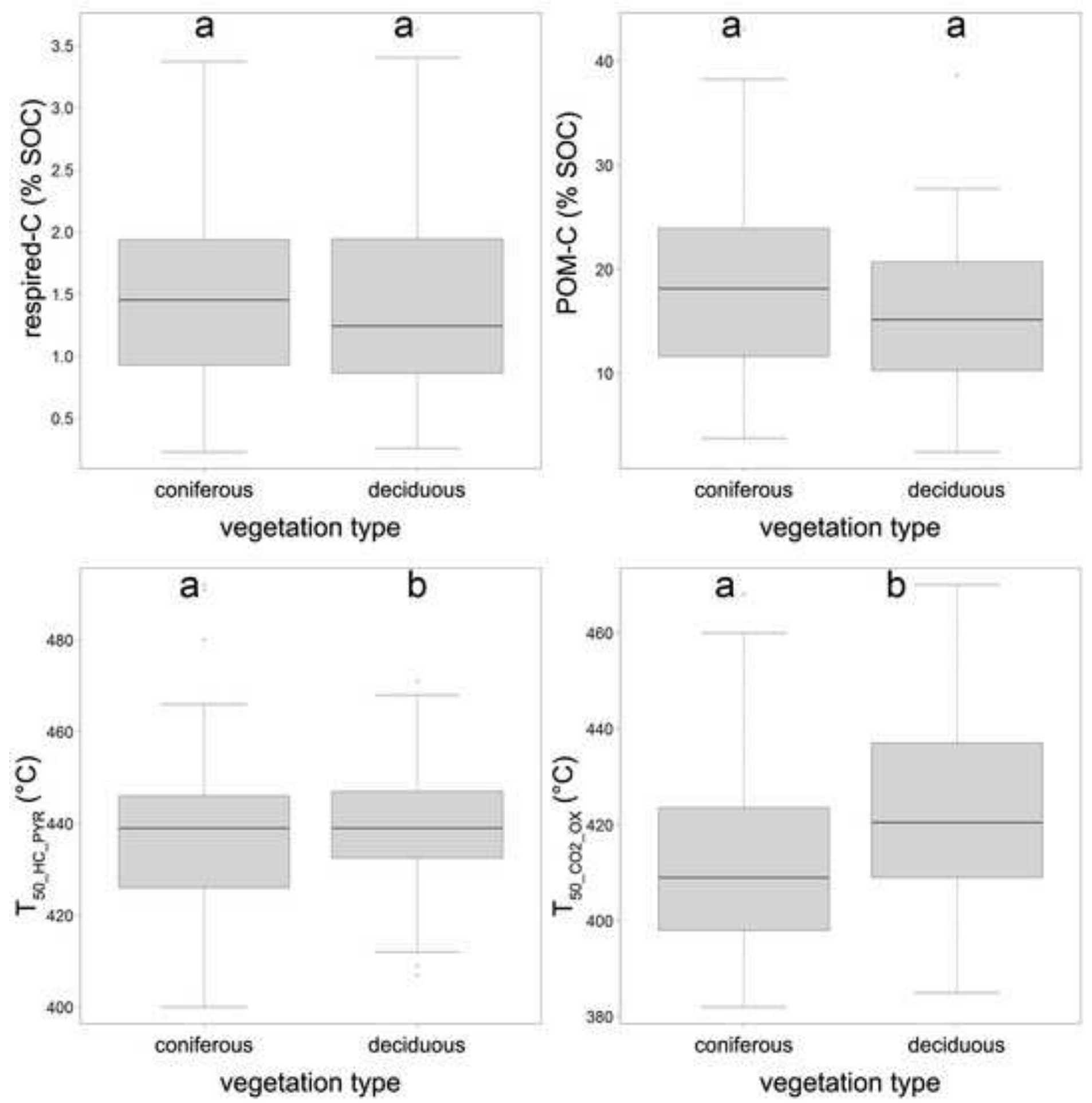


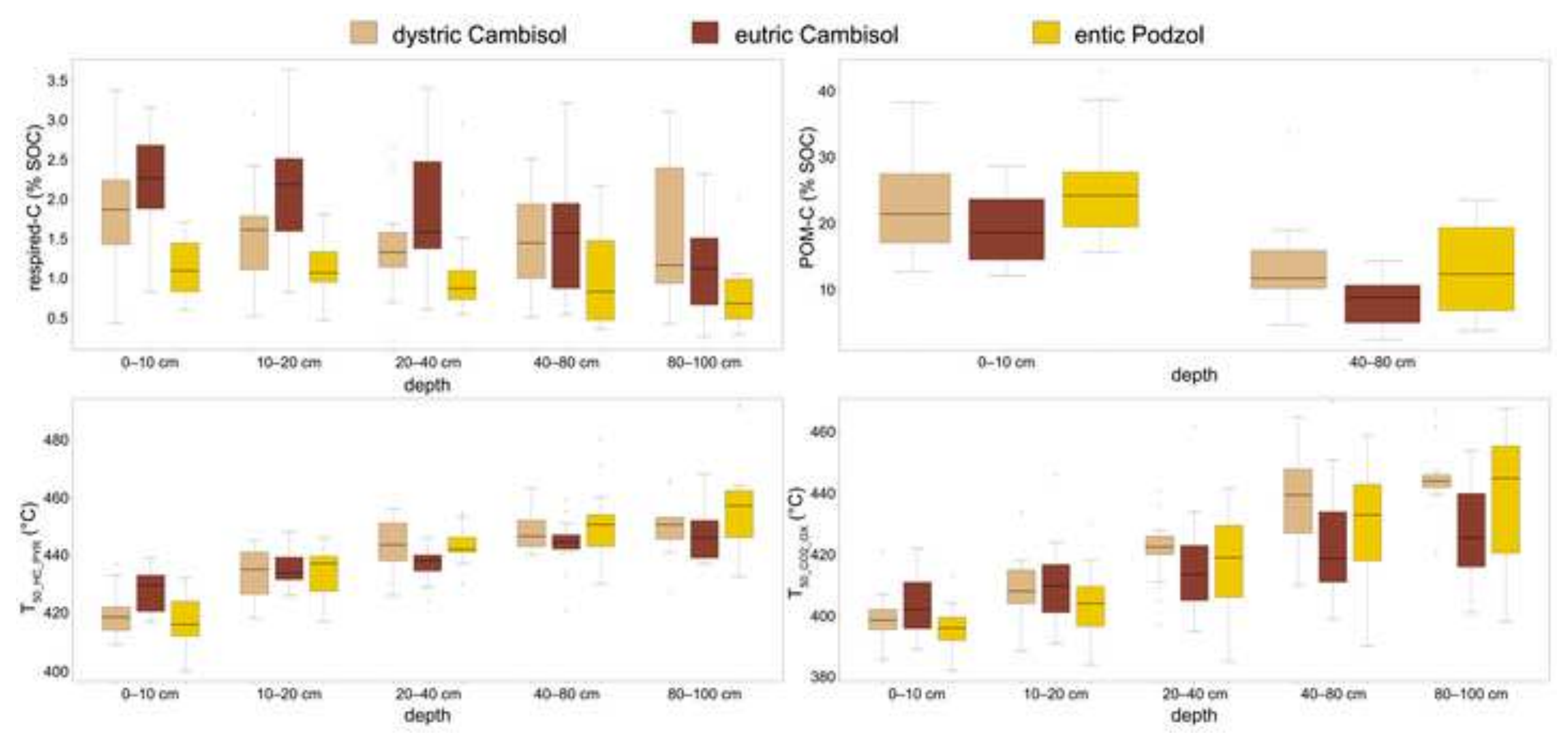
depth
400

Click here to download colour figure Fig4.tif $\underline{\underline{\underline{ }}}$ 


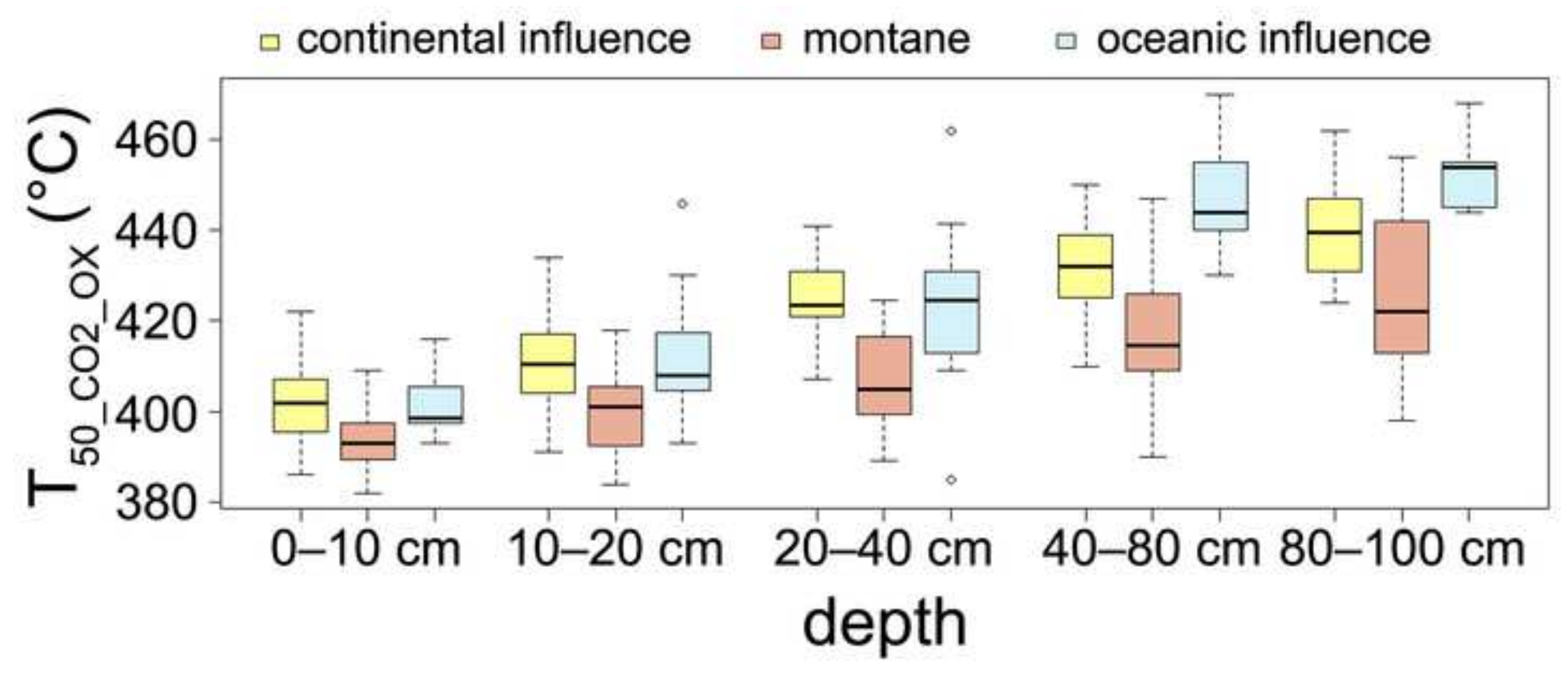



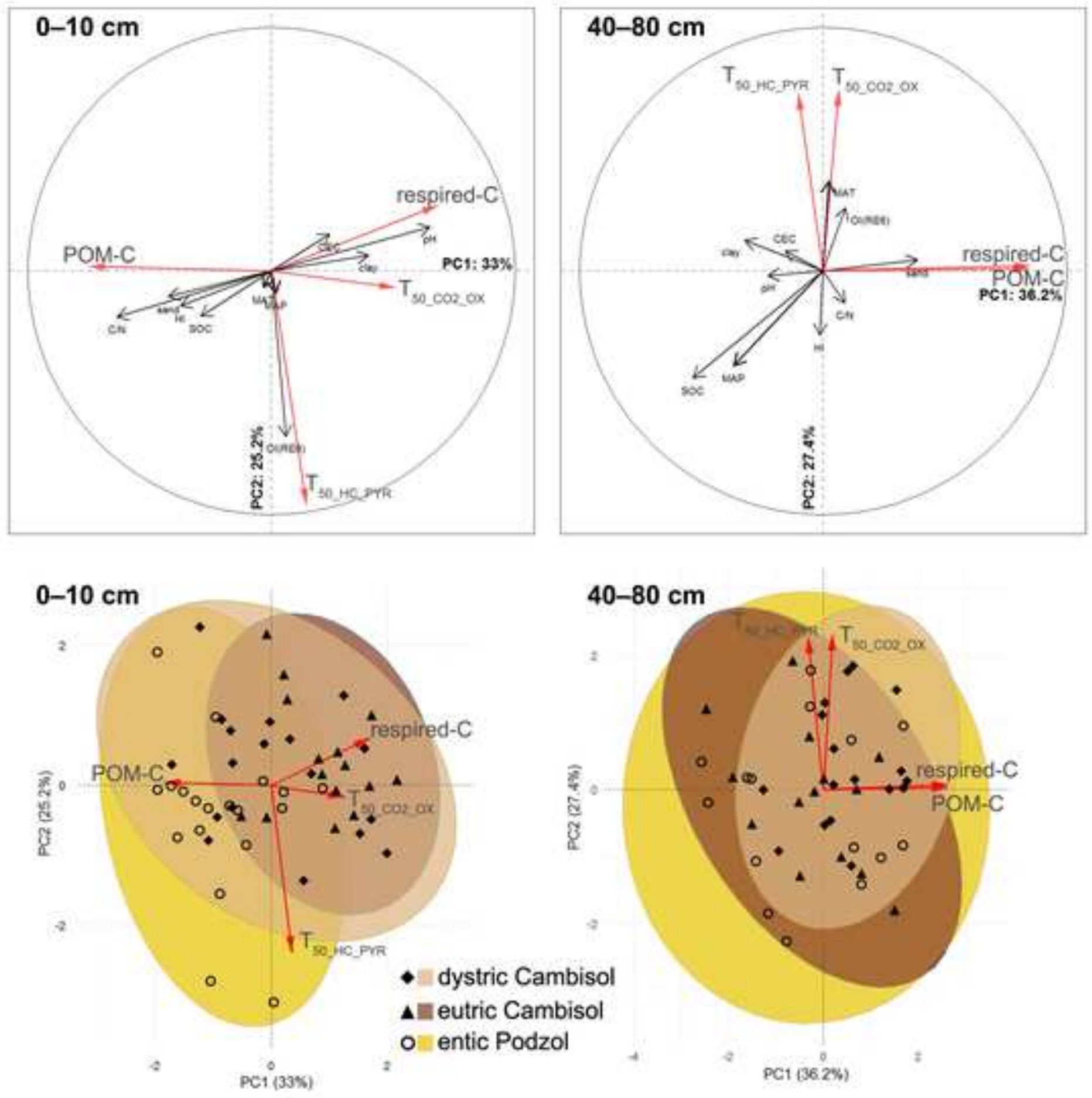


\section{Supplementary material captions}

Online Resource 1 Description of the Rock-Eval 6 thermal analysis (adapted from Baudin et al., 2017) and calculation of the two RE6-derived parameters (hydrogen index; T50_CO2_ox, the temperature at which $50 \%$ of the residual SOM was oxidized to $\mathrm{CO}_{2}$ during the oxidation phase)

Baudin F, Tribovillard N, Trichet J (2017) Géologie De La Matière Organique. EDP Sciences, Lilles, France.

Online Resource 2 Correlation between C content (\%) of isovolumetrically pooled samples (measured in this study as detailed in Materials and Methods subsection a) and average values of the 5 replicates $\times 5$ subplots from RENECOFOR samples (calculated with values from Jonard et al. (2017) and Ponette et al. (1997) for samples 0-40cm and 40-100 cm, respectively) for a given soil layer $(n=242)$. The 1:1 line has been added in red for reference

Jonard M, Nicolas M, Coomes DA, Caignet I, Saenger A, Ponette Q (2017) Forest soils in France are sequestering substantial amounts of carbon. Sci Total Environ 574:616-628

Ponette Q, Ulrich E, Brêthes A, Bonneau M, Lanier M (1997) RENECOFOR - Chimie des sols dans les 102 peuplements du réseau : campagne de mesures 1993-95. ONF, Département des recherches techniques, Fontainebleau, France

Online Resource 3 Details of models and their significant terms selected to explain variations in respired-C and POM-C, $\mathrm{T}_{50}{ }_{-} \mathrm{HC}_{-} \mathrm{PYR}$, and $\mathrm{T}_{50} \mathrm{CO}_{2} \mathrm{OX}$ in the 53 study plots (analysis by profile). All models used a gls function (see details in the Calculations and statistical analyses section) 
Online Resource 4 Mean (and standard deviation) of the indicators of labile SOC ( $\mathrm{T}_{50 \_H C}$ PYR, $\mathrm{POM}-\mathrm{C}$; respired-C) and stable $\mathrm{SOC}\left(\mathrm{T}_{50 \_} \mathrm{CO}_{2} \mathrm{OX}\right)$ for each soil class in the five different layers. The total SOC content was added for reference

Online Resource 5 Table of correlations for all samples and for each layer individually between the indicators of the SOC pools and the physico-chemical properties (SOC content, $\mathrm{C} / \mathrm{N}$ ratio, $\mathrm{HI}$, OIRE6, texture, $\mathrm{pH}$, cationic exchange capacity), the climatic data of the plots (mean annual precipitation; MAP and mean annual temperature; MAT) and the chemical properties $(\mathrm{C} / \mathrm{N}$ ratio) of the inputs and humus. Significance is indicated as follows: $* * *: \mathrm{p}<$ $0.001 ; * *: \mathrm{p}<0.01{ }^{*}: \mathrm{p}<0.05$. The high $(>0.6)$ correlations obtained with the SOC pools indicators are marked in bold. $n=242$ total; $n=53$ for layers 1 to 3 and $n=50$ and $n=33$ for layers 4 and 5 respectively unless specified otherwise

Online Resource 6 Distribution of the mean annual precipitation (MAP) and mean annual temperature (MAT) in the 53 study sites as a function of vegetation type illustrating a bias towards coniferous stands being in wetter and colder locations. $n=29$ and 24 for coniferous and deciduous, respectively 
hydrogen index ( $\mathrm{HI} ; \mathrm{mg} \mathrm{HC} / \mathrm{g} \mathrm{C})$

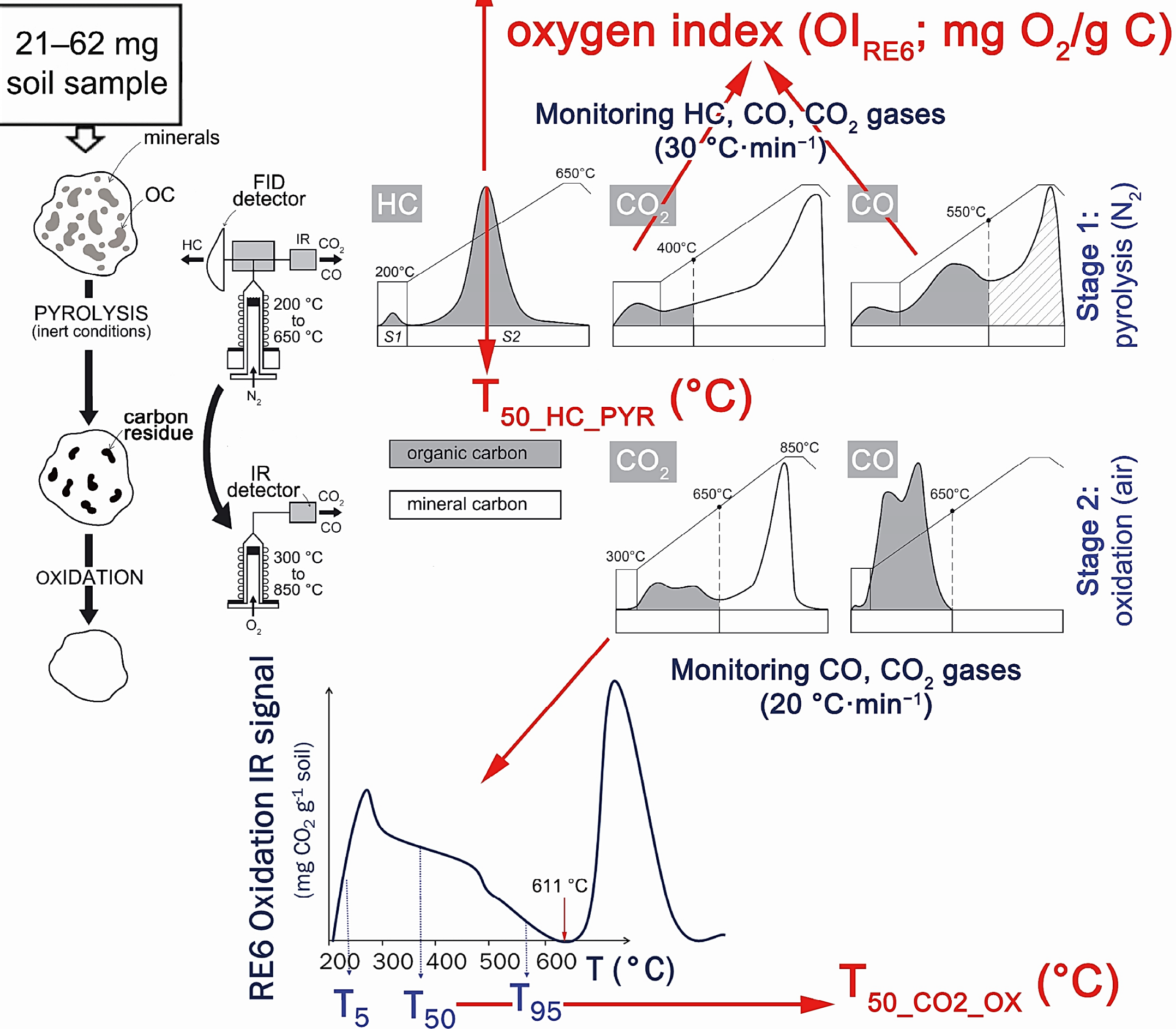




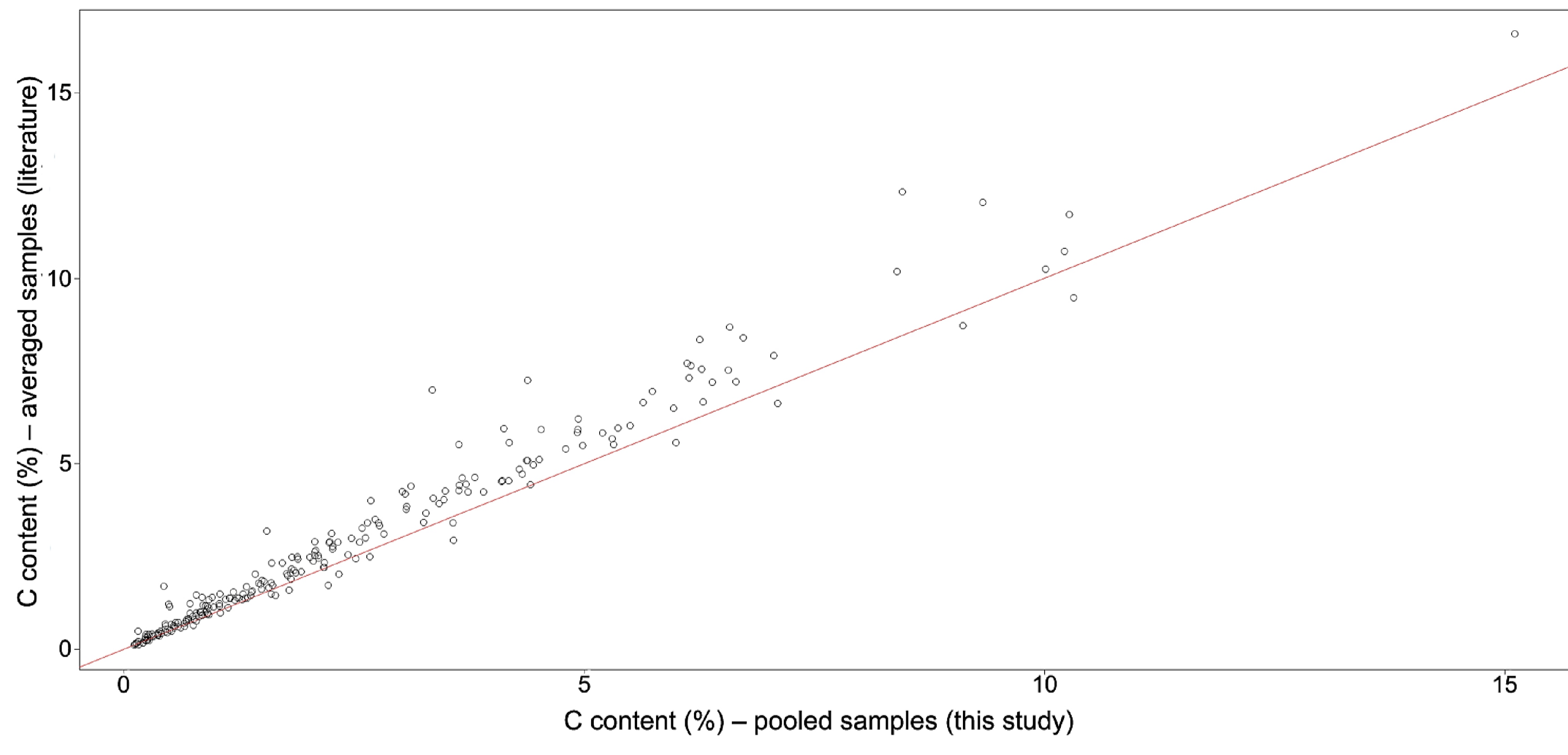


Online Resource 3 Details of models and their significant terms selected to explain variations in

respired-C and POM-C, $\mathrm{T}_{50} \mathrm{HC}_{-} \mathrm{PYR}$, and $\mathrm{T}_{50 \_\mathrm{CO} 2} \mathrm{OX}$ in the 53 study plots (analysis by profile). All models

used a gls function (see details in the Calculations and statistical analyses section)

\begin{tabular}{|c|c|c|c|}
\hline $\begin{array}{l}\text { Response } \\
\text { variable }\end{array}$ & Transformation & $\begin{array}{l}\text { Predictors in final } \\
\text { model }^{\$}\end{array}$ & $\begin{array}{l}\text { Level of significance } \\
p \text {-value }\end{array}$ \\
\hline respired-C & $\log _{10}($ respired-C + 1) & $\begin{array}{l}\text { soil }+ \text { depth }+ \text { soil } \times \\
\text { depth }\end{array}$ & $\begin{array}{l}\text { soil }<0.0001 ; \text { depth }=0.0823 ; \text { depth } \times \text { soil }= \\
0.0417\end{array}$ \\
\hline POM-C & $\log _{10}(\mathrm{POM}-\mathrm{C})$ & depth + soil & depth $<0.0001$ and soil $=0.0114$ \\
\hline $\mathrm{T}_{50 \_\mathrm{HC} \_ \text {PYR }}$ & & $\begin{array}{l}\text { depth }+ \text { soil }+ \text { veg }+ \\
\text { depth } \times \text { soil }+ \text { depth } \\
\times \text { veg }+ \text { soil } \times \text { veg }\end{array}$ & $\begin{array}{l}\text { depth and depth } \times \text { soil }<0.0001 ; \text { soil }=0.1440 ; \text { veg } \\
=0.0665 ; \text { depth } \times \text { veg }=0.0023 ; \text { soil } \times \text { veg }= \\
0.0236\end{array}$ \\
\hline $\mathrm{T}_{50 \_\mathrm{CO} 2 \_\mathrm{OX}}$ & & $\begin{array}{l}\text { depth }+ \text { veg }+ \\
\text { climate }+ \text { depth } \times \\
\text { climate }\end{array}$ & all $<0.0001$ except climate $=0.0272$ \\
\hline
\end{tabular}

${ }^{\$}$ For all models, as a preliminary inspection of the variance of a given factor showed heterogeneity among the various layers, we used a constant variance function [varIdent(form $=\sim 1 \mid$ depth)], which allowed five different variances, one for each soil layer. We also used the compound symmetry structure [corCompSymm(form $=\sim 1 \mid$ plot)], which is similar to the variance structure of a random-intercept-only model. In our case, it allowed to treat each site as random factor. 


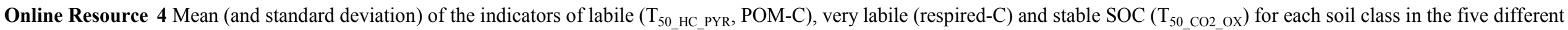
layers. The basic soil physico-chemical properties (texture, total SOC content, $\mathrm{C} / \mathrm{N}$ ratio and $\mathrm{pH}$ ) were added for reference

\begin{tabular}{|c|c|c|c|c|c|c|c|c|c|c|c|c|c|c|c|c|c|c|c|c|c|c|c|c|c|}
\hline \multirow{2}{*}{$\begin{array}{l}\text { layer } \\
0-10 \mathrm{~cm}\end{array}$} & \multirow{2}{*}{$\begin{array}{l}\text { soil class } \\
\text { ALL }\end{array}$} & \multirow{2}{*}{$\frac{\mathrm{n}}{53}$} & \multicolumn{2}{|c|}{$\mathrm{T}_{50 \_ \text {HC_PYR }}\left({ }^{\circ} \mathrm{C}\right)$} & \multicolumn{2}{|c|}{ 50_CO2_ox $\left({ }^{\circ} \mathrm{C}\right)$} & \multirow[t]{2}{*}{$\mathrm{n}$} & \multicolumn{2}{|c|}{$\begin{array}{c}\text { POM-C (\% } \\
\text { OC) }\end{array}$} & $\mathrm{n}$ & \multicolumn{2}{|c|}{$\begin{array}{l}\text { respired-C ( } \mu \mathrm{g} \\
\mathrm{CO} 2-\mathrm{C} \cdot \mu \mathrm{g}^{-1} \text { soil } \\
\mathrm{C} \text { in } \%)\end{array}$} & \multirow{2}{*}{$\frac{\mathrm{n}}{53}$} & \multicolumn{2}{|c|}{ clay (\%) } & \multicolumn{2}{|c|}{ silt (\%) } & \multicolumn{2}{|c|}{ sand (\%) } & \multicolumn{2}{|c|}{$\mathrm{C}$ content $(\%)$} & \multicolumn{2}{|c|}{$\mathrm{C} / \mathrm{N}$ ratio } & \multicolumn{2}{|c|}{$\mathrm{pH}$} \\
\hline & & & 422 & (8) & 399 & (8) & & 22.6 & $(7.3)$ & 53 & 1.73 & $(0.57)$ & & 22 & (14) & 36 & (18) & 42 & (29) & 5.1 & $(2.7)$ & 16.9 & $(4.5)$ & 4.9 & $(1.0)$ \\
\hline & dystric Cambisol & 18 & 420 & (8) & 399 & (8) & 18 & 23.0 & $(7.5)$ & 18 & 1.87 & $(0.70)$ & 18 & 18 & (9) & 31 & (14) & 51 & $(21)$ & 4.1 & $(1.8)$ & 16.8 & (3.4) & 4.5 & $(0.3)$ \\
\hline & eutric Cambisol & 16 & 428 & (7) & 403 & (10) & 16 & 19.2 & (5.6) & 16 & 2.19 & $(0.62)$ & 16 & 37 & (11) & 50 & (13) & 13 & $(20)$ & 5.1 & (1.9) & 13.3 & $(1.5)$ & 6.2 & $(0.9)$ \\
\hline & entic Podzol & 19 & 417 & (9) & 396 & (8) & 19 & 25.1 & (7.6) & 19 & 1.13 & $(0.38)$ & 19 & 15 & (9) & 28 & (19) & 57 & $(25)$ & 6 & (3.6) & 19.9 & $(5.0)$ & 4.1 & $(0.2)$ \\
\hline \multirow[t]{4}{*}{$10-20 \mathrm{~cm}$} & ALL & 53 & 434 & (7) & 408 & (12) & & nd & & 53 & 1.61 & $(0.56)$ & 53 & 21 & (13) & 37 & (18) & 42 & (29) & 2.9 & $(2.0)$ & 16.4 & (4.9) & 5.1 & (1.1) \\
\hline & dystric Cambisol & 18 & 434 & (8) & 409 & (10) & & nd & & 18 & 1.54 & $(0.64)$ & 18 & 17 & (9) & 32 & (14) & 51 & (21) & 1.9 & $(0.7)$ & 16.3 & (3.5) & 4.6 & $(0.3)$ \\
\hline & eutric Cambisol & 16 & 435 & (6) & 410 & (14) & & nd & & 16 & 2.13 & $(0.74)$ & 16 & 36 & (11) & 51 & (11) & 13 & (17) & 3.5 & (1.6) & 12.4 & $(1.1)$ & 6.5 & (1.0) \\
\hline & entic Podzol & 19 & 433 & (8) & 404 & (11) & & nd & & 19 & 1.15 & $(0.31)$ & 19 & 13 & (7) & 29 & (20) & 58 & $(25)$ & 3.3 & $(2.7)$ & 19.8 & (5.4) & 4.3 & $(0.2)$ \\
\hline \multirow[t]{4}{*}{$20-40 \mathrm{~cm}$} & ALL & 53 & 441 & (7) & 418 & (15) & & nd & & 53 & 1.43 & $(0.68)$ & 53 & 20 & (14) & 36 & (18) & 43 & (28) & 1.8 & (1.4) & 14.8 & (4.3) & 5.4 & (1.3) \\
\hline & dystric Cambisol & 18 & 444 & (8) & 421 & (10) & & nd & & 18 & 1.38 & $(0.61)$ & 18 & 17 & (9) & 33 & (14) & 51 & (21) & 1.1 & $(0.4)$ & 14.8 & (3.8) & 4.8 & $(0.3)$ \\
\hline & eutric Cambisol & 16 & 437 & (5) & 417 & (16) & & nd & & 16 & 1.86 & $(0.84)$ & 16 & 35 & (13) & 48 & (12) & 17 & (17) & 2.4 & (1.4) & 11.3 & $(1.3)$ & 7.2 & (1.0) \\
\hline & entic Podzol & 19 & 443 & (6) & 417 & (17) & & nd & & 19 & 1.06 & $(0.58)$ & 19 & 11 & (6) & 30 & (20) & 59 & (25) & 2.1 & (1.8) & 17.7 & $(4.3)$ & 4.6 & $(0.1)$ \\
\hline \multirow[t]{4}{*}{$40-80 \mathrm{~cm}$} & ALL & 50 & 448 & (10) & 431 & (17) & 50 & 11.5 & $(6.2)$ & 46 & 1.34 & $(0.67)$ & 50 & 20 & (15) & 32 & (17) & 48 & (27) & 0.8 & $(0.8)$ & 11.6 & $(3.8)$ & 5.8 & (1.4) \\
\hline & dystric Cambisol & 18 & 449 & (7) & 438 & (15) & 18 & 13.3 & $(6.3)$ & 17 & 1.48 & $(0.62)$ & 18 & 18 & (10) & 28 & (11) & 54 & (19) & 0.5 & $(0.3)$ & 10.5 & (3.5) & 5.1 & $(0.6)$ \\
\hline & eutric Cambisol & 14 & 444 & (9) & 424 & (19) & 14 & 7.8 & $(3.5)$ & 14 & 1.51 & $(0.75)$ & 14 & 35 & (18) & 41 & (13) & 24 & $(25)$ & 0.9 & $(0.5)$ & 9.3 & (1.9) & 7.9 & (0.6) \\
\hline & entic Podzol & 18 & 450 & (12) & 430 & (18) & 18 & 12.5 & $(6.8)$ & 15 & 1.03 & $(0.64)$ & 18 & 11 & (5) & 28 & (20) & 62 & $(25)$ & 1.1 & (1.1) & 14.6 & (3.4) & 4.8 & $(0.2)$ \\
\hline \multirow[t]{4}{*}{$80-100 \mathrm{~cm}$} & ALL & 33 & 452 & (13) & 437 & (17) & & nd & & 31 & 1.17 & $(0.66)$ & 33 & 22 & (17) & 34 & (16) & 44 & (27) & 0.6 & $(0.5)$ & 9.7 & $(4.0)$ & 6.1 & (1.6) \\
\hline & dystric Cambisol & 11 & 450 & (11) & 445 & (12) & & nd & & 11 & 1.57 & $(0.91)$ & 11 & 20 & (11) & 30 & (12) & 50 & (19) & 0.3 & $(0.2)$ & 7.2 & (1.9) & 5.3 & (1.0) \\
\hline & eutric Cambisol & 10 & 448 & (11) & 427 & (16) & & nd & & 10 & 1.14 & $(0.59)$ & 10 & 38 & (19) & 41 & (12) & 21 & (23) & 0.7 & $(0.2)$ & 8.4 & (1.6) & 8.2 & $(0.6)$ \\
\hline & entic Podzol & 12 & 458 & (18) & 439 & $(22)$ & & nd & & 10 & 0.79 & $(0.49)$ & 12 & 10 & (4) & 30 & (21) & 59 & (23) & 0.8 & $(0.7)$ & 13.1 & $(4.6)$ & 5.0 & $(0.4)$ \\
\hline $0-100 \mathrm{~cm}$ & ALL & 242 & 439 & (9) & 419 & (14) & 103 & 17.2 & $(8.8)$ & 236 & 1.46 & $(0.63)$ & 242 & 21 & (14) & 35 & (17) & 44 & (28) & 2.4 & (2.4) & 14.2 & $(5.0)$ & 5.4 & (1.3) \\
\hline
\end{tabular}




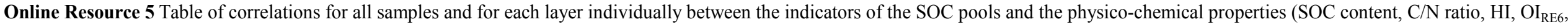

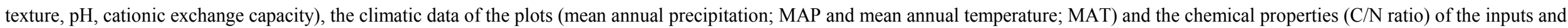

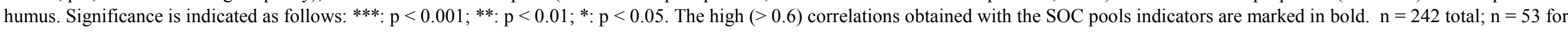
layers 1 to 3 and $n=50$ and $n=33$ for layers 4 and 5 respectively unless specified otherwise

\begin{tabular}{|c|c|c|c|c|c|c|c|c|c|c|c|c|c|c|c|}
\hline & POM-C ${ }^{\S}$ & respired-C ${ }^{*}$ & $\mathrm{~T}_{50 \_ \text {HC_PYR }}$ & $\mathrm{T}_{50 \_\mathrm{CO} 2 \mathrm{OX}}$ & $\mathrm{SOC}$ & $\mathrm{C} / \mathrm{N}$ ratio (soil) & $\mathrm{HI}$ & $\mathrm{OI}_{\mathrm{RE} 6}$ & Clay & Sand & $\mathrm{pH}_{\text {water }}$ & $\mathrm{CEC}$ & MAP & MAT & $\mathrm{C} / \mathrm{N}$ ratio (inputs) \\
\hline respired-C & 0.20 & & & & & & & & & & & & & & \\
\hline $\mathrm{T}_{50 \_ \text {HC_PYR }}$ & $-0.73 * * *$ & $-0.32 * * *$ & & & & & & & & & & & & & \\
\hline $\mathrm{T}_{50 \_\mathrm{CO} 2 \_\mathrm{OX}}$ & $-0.56^{* * *}$ & $-0.15^{*}$ & $0.67^{* * *}$ & & & & & & & & & & & & \\
\hline SOC & $0.52 * * *$ & 0.03 & $-0.58^{* * *}$ & $-0.72 * * *$ & & & & & & & & & & & \\
\hline $\mathrm{C} / \mathrm{N}$ ratio (soil) & $0.61^{* * *}$ & $-0.13^{*}$ & $-0.34 * * *$ & $-0.43^{* * *}$ & $0.42 * * *$ & & & & & & & & & & \\
\hline HI & $0.67^{* * *}$ & 0.08 & $-0.67 * * *$ & $-0.53 * * *$ & $0.58 * * *$ & $0.62 * * *$ & & & & & & & & & \\
\hline $\mathrm{OI}_{\mathrm{RE} 6}$ & $-0.76 * * *$ & -0.04 & $0.63^{* * *}$ & $0.50^{* * *}$ & $-0.56^{* * *}$ & $-0.78 * * *$ & $-0.84 * * *$ & & & & & & & & \\
\hline Clay & -0.18 & $0.19 * *$ & -0.06 & -0.03 & $0.31 * * *$ & $-0.51 * * *$ & $-0.16^{*}$ & $0.31 * * *$ & & & & & & & \\
\hline Sand & 0.18 & $-0.15^{*}$ & 0.02 & 0.10 & $-0.32 * * *$ & $0.45 * * *$ & $0.14^{*}$ & $-0.28 * * *$ & $-0.89 * * *$ & & & & & & \\
\hline $\mathrm{pH}_{\text {water }}$ & $-0.54 * * *$ & $0.23 * * *$ & $0.31^{* * *}$ & $0.33^{* * *}$ & $-0.22 * * *$ & $-0.61^{* * *}$ & $-0.45^{* * *}$ & $0.59^{* * *}$ & $0.44 * * *$ & $-0.45^{* * *}$ & & & & & \\
\hline $\mathrm{CEC}$ & 0.08 & $0.31 * * *$ & $-0.33 * * *$ & $-0.25^{* * *}$ & $0.48 * * *$ & $-0.31 * * *$ & $0.14^{*}$ & 0.06 & $0.74 * * *$ & $-0.69 * * *$ & $0.47 * * *$ & & & & \\
\hline MAP & -0.11 & $-0.16^{*}$ & 0.06 & $-0.20 * *$ & $0.36^{* * *}$ & -0.01 & -0.06 & 0.12 & $0.14^{*}$ & $-0.17 * *$ & 0.07 & 0.12 & & & \\
\hline MAT & -0.02 & -0.09 & 0.01 & $0.19 * *$ & $-0.25 * * *$ & -0.02 & $0.13^{*}$ & -0.11 & -0.08 & 0.06 & $-0.22 * * *$ & $-0.22 * * *$ & $-0.60 * * *$ & & \\
\hline $\mathrm{C} / \mathrm{N}$ ratio (inputs) & $0.22 *$ & $0.16^{*}$ & -0.09 & $-0.16^{*}$ & -0.07 & $0.24 * * *$ & -0.05 & -0.06 & $-0.24 * * *$ & $0.23^{* * *}$ & -0.03 & $-0.17 * *$ & $-0.24 * * *$ & -0.08 & \\
\hline \multirow[t]{2}{*}{$\mathrm{C} / \mathrm{N}$ ratio (humus) } & 0.01 & $0.38^{* * *}$ & $-0.14^{*}$ & -0.11 & -0.01 & -0.03 & -0.08 & 0.10 & 0.12 & $-0.14 *$ & $0.40^{* * *}$ & $0.18 * *$ & -0.05 & -0.06 & $0.44 * * *$ \\
\hline & $\S \mathrm{n}=99$ & ${ }^{*} \mathrm{n}=236$ & & & & & & & & & & & & & \\
\hline \multicolumn{16}{|c|}{ LAYER 1: 0-10 cm } \\
\hline & POM-C & respired-C & $\mathrm{T}_{50 \_ \text {HC_PYR }}$ & $\mathrm{T}_{50 \_\mathrm{CO} 2 \_\mathrm{OX}}$ & SOC & $\mathrm{C} / \mathrm{N}$ ratio (soil) & $\mathrm{HI}$ & $\mathrm{OI}_{\mathrm{RE} 6}$ & Clay & Sand & $\mathrm{pH}_{\text {water }}$ & CEC & MAP & MAT & $\mathrm{C} / \mathrm{N}$ ratio (inputs) \\
\hline respired-C & $-0.29 *$ & & & & & & & & & & & & & & \\
\hline $\mathrm{T}_{50 \_ \text {HC_PYR }}$ & $-0.44 * * *$ & 0.12 & & & & & & & & & & & & & \\
\hline $\mathrm{T}_{50 \_\mathrm{CO} 2 \_\mathrm{OX}}$ & -0.19 & 0.13 & $0.45^{* * *}$ & & & & & & & & & & & & \\
\hline $\mathrm{SOC}$ & 0.17 & -0.20 & -0.10 & $-0.28^{*}$ & & & & & & & & & & & \\
\hline $\mathrm{C} / \mathrm{N}$ ratio (soil) & $0.56^{* * *}$ & $-0.51 * * *$ & $-0.55^{* * *}$ & -0.19 & -0.08 & & & & & & & & & & \\
\hline HI & $0.32 *$ & $-0.43 * *$ & $-0.30^{*}$ & 0.07 & $-0.29 *$ & $0.67 * * *$ & & & & & & & & & \\
\hline $\mathrm{OI}_{\mathrm{RE} 6}$ & $-0.41^{* *}$ & $0.52 * * *$ & $0.40^{* *}$ & -0.06 & 0.25 & $-0.80 * * *$ & $-0.91 * * *$ & & & & & & & & \\
\hline Clay & $-0.29 *$ & $0.43 * *$ & $0.44 * *$ & -0.03 & $0.44 * *$ & $-0.70 * * *$ & $-0.71 * * *$ & $0.75 * * *$ & & & & & & & \\
\hline Sand & $0.32 *$ & $-0.41^{* *}$ & $-0.50 * * *$ & -0.08 & $-0.32 *$ & $0.65 * * *$ & $0.61 * * *$ & $-0.65 * * *$ & $-0.88 * * *$ & & & & & & \\
\hline $\mathrm{pH}_{\text {water }}$ & $-0.35^{* *}$ & $0.62^{* * *}$ & $0.46^{* * *}$ & $0.36^{* *}$ & 0.06 & $-0.70 * * *$ & $-0.61 * * *$ & $0.70^{* * *}$ & $0.60 * * *$ & $-0.62 * * *$ & & & & & \\
\hline CEC & -0.16 & $0.30^{*}$ & $0.35^{*}$ & 0.00 & $0.60^{* * *}$ & $-0.60 * * *$ & $-0.72 * * *$ & $0.72 * * *$ & $0.78^{* * *}$ & $-0.72 * * *$ & $0.64 * * *$ & & & & \\
\hline MAP & -0.10 & 0.10 & -0.11 & $-0.29 *$ & $0.53 * * *$ & -0.25 & $-0.37 * *$ & $0.35^{*}$ & $0.33^{*}$ & -0.21 & 0.06 & $0.39 * *$ & & & \\
\hline MAT & -0.09 & $-0.30^{*}$ & 0.14 & 0.25 & $-0.39^{* *}$ & 0.10 & $0.32 *$ & $-0.30^{*}$ & -0.26 & 0.13 & -0.21 & $-0.45^{* * *}$ & $-0.61 * * *$ & & \\
\hline $\mathrm{C} / \mathrm{N}$ ratio (inputs) & $0.31^{*}$ & -0.03 & $-0.41^{* *}$ & -0.25 & -0.07 & $0.47 * * *$ & -0.02 & -0.13 & -0.26 & $0.28^{*}$ & -0.14 & -0.16 & -0.25 & -0.06 & \\
\hline $\mathrm{C} / \mathrm{N}$ ratio (humus) & -0.04 & $0.47 * * *$ & -0.10 & 0.10 & -0.17 & -0.07 & $-0.41 * *$ & $0.34 *$ & 0.11 & -0.16 & $0.42 * *$ & 0.14 & -0.05 & -0.07 & $0.45^{* * *}$ \\
\hline
\end{tabular}




\section{LAYER 2: 10-20 cm}

\begin{tabular}{|c|c|c|c|c|c|c|c|c|c|c|c|c|c|c|c|}
\hline & POM-C & respired-C & $\mathrm{T}_{50 \_ \text {HC_PYR }}$ & $\mathrm{T}_{50 \_\mathrm{CO} 2 \_\mathrm{OX}}$ & $\mathrm{SOC}$ & $\mathrm{C} / \mathrm{N}$ ratio (soil) & $\mathrm{HI}$ & $\mathrm{OI}_{\mathrm{RE} 6}$ & Clay & Sand & $\mathrm{pH}_{\text {water }}$ & $\mathrm{CEC}$ & MAP & MAT & $\mathrm{C} / \mathrm{N}$ ratio (inputs) \\
\hline respired-C & nd & & & & & & & & & & & & & & \\
\hline $\mathrm{T}_{50 \_ \text {HC_PYR }}$ & nd & 0.00 & & & & & & & & & & & & & \\
\hline $\mathrm{T}_{50 \_\mathrm{CO} 2 \mathrm{OX}}$ & nd & 0.02 & $0.40^{* *}$ & & & & & & & & & & & & \\
\hline SOC & nd & -0.13 & 0.08 & -0.09 & & & & & & & & & & & \\
\hline $\mathrm{C} / \mathrm{N}$ ratio (soil) & nd & $-0.33^{*}$ & -0.13 & -0.04 & $-0.34 *$ & & & & & & & & & & \\
\hline HI & nd & -0.24 & -0.26 & 0.14 & $-0.28^{*}$ & $0.60 * * *$ & & & & & & & & & \\
\hline $\mathrm{OI}_{\mathrm{RE} 6}$ & nd & $0.34^{*}$ & 0.21 & -0.22 & $0.37^{* *}$ & $-0.73 * * *$ & $-0.74 * * *$ & & & & & & & & \\
\hline Clay & nd & $0.29 *$ & 0.10 & 0.07 & $0.60^{* * *}$ & $-0.71 * * *$ & $-0.53 * * *$ & $0.65 * * *$ & & & & & & & \\
\hline Sand & nd & $-0.29 *$ & -0.12 & -0.05 & $-0.52 * * *$ & $0.66^{* * *}$ & $0.44 * *$ & $-0.58 * * *$ & $-0.88 * * *$ & & & & & & \\
\hline $\mathrm{pH}_{\text {water }}$ & nd & $0.60 * * *$ & 0.08 & $0.29^{*}$ & $0.28^{*}$ & $-0.62 * * *$ & $-0.36^{* *}$ & $0.51 * * *$ & $0.59 * * *$ & $-0.58 * * *$ & & & & & \\
\hline CEC & nd & $0.27^{*}$ & 0.13 & -0.01 & $0.73 * * *$ & $-0.65 * * *$ & $-0.40^{* *}$ & $0.60 * * *$ & $0.76^{* * *}$ & $-0.77 * * *$ & $0.64 * * *$ & & & & \\
\hline MAP & nd & -0.08 & -0.06 & -0.24 & $0.66^{* * *}$ & -0.20 & -0.17 & 0.23 & $0.30^{*}$ & -0.24 & 0.10 & $0.39 * *$ & & & \\
\hline MAT & nd & -0.20 & -0.05 & 0.21 & $-0.47 * * *$ & 0.12 & 0.25 & $-0.29 *$ & -0.20 & 0.12 & -0.27 & $-0.42 * *$ & $-0.61 * * *$ & & \\
\hline $\mathrm{C} / \mathrm{N}$ ratio (inputs) & nd & 0.20 & -0.05 & -0.25 & -0.21 & $0.32 *$ & -0.12 & 0.02 & -0.26 & $0.28^{*}$ & -0.05 & -0.23 & -0.25 & -0.06 & \\
\hline $\mathrm{C} / \mathrm{N}$ ratio (humus) & nd & $0.53 * * *$ & -0.12 & -0.01 & -0.02 & -0.14 & -0.22 & $0.27 *$ & 0.14 & -0.15 & $0.51^{* * *}$ & 0.11 & -0.05 & -0.07 & $0.45^{* * *}$ \\
\hline
\end{tabular}

LAYER 3: $20-40 \mathrm{~cm}$

\begin{tabular}{|c|c|c|c|c|c|c|c|c|c|c|c|c|}
\hline POM-C & respired-C & $\mathrm{T}_{50 \_\mathrm{HC} \_\mathrm{PYR}}$ & $\mathrm{T}_{50 \_\mathrm{CO} 2 \mathrm{OX}} \mathrm{SOC}$ & $\mathrm{C} / \mathrm{N}$ ratio (soil) & $\mathrm{HI}$ & $\mathrm{OI}_{\mathrm{RE} 6}$ & Clay & Sand & $\mathrm{pH}_{\text {water }}$ & CEC & MAP & MAT $\mathrm{C} / \mathrm{N}$ ratio (inputs) \\
\hline
\end{tabular}

respired-C

$\mathrm{T}_{50 \_ \text {HC_PYR }}$

$\mathrm{T}_{50 \_ \text {CO2_OX }}$

SOC

$\mathrm{C} / \mathrm{N}$ ratio (soil)

$\mathrm{HI}$

$\mathrm{OI}_{\mathrm{RE} 6}$

Clay

Sand

$\mathrm{pH}_{\text {water }}$

CEC

MAP

MAT

nd $\quad-0.33^{*}$

nd $\quad 0.06 \quad 0.37$ **

nd $\quad-0.21 \quad-0.12 \quad-0.41^{\text {** }}$

nd $\quad-0.27 \quad 0.21$

$\begin{array}{rr}-0.27 & 0.21 \\ -0.10 & -0.21\end{array}$

$0.11-0.05$

0.06

$0.29 * \quad-0.22$

$-0.23 \quad 0.21$

$0.05 \quad 0.13 \quad 0.48 * * *$

$-0.31^{*} \quad 0.20 \quad-0.76^{* * *}$

$-0.04 \quad 0.46^{* * *}-0.74 * * *$

$0.15-0.48^{* * *} \quad 0.68^{* * *}$

$-0.65^{* * *}$

$0.45^{* * *} \quad-0.32^{*}$

$0.29 *-0.47 * * *$

$0.24-0.64 * * *-0.90^{* * *}$

$\begin{array}{llll}-0.11 & 0.40 * * & 0.54 * * * & -0.50 * * *\end{array}$

$\begin{array}{cclllclll}0.19 & -0.30^{*} & -0.24 & 0.62^{* * *} & -0.59^{* * *} & -0.13 & 0.51^{* * *} & 0.77^{* * *} & -0.76^{* * *} \\ -0.15 & 0.02 & -0.38^{* *} & 0.72^{* * *} & -0.05 & 0.10 & 0.11 & 0.20 & -0.25\end{array}$

$\begin{array}{lllll}0.00 & -0.07 & 0.33^{*} & -0.49^{* * *} & 0.03\end{array}$

$-0.25 \quad 0.65^{* * *}$

$\mathrm{C} / \mathrm{N}$ ratio (inputs) nd

$0.04 \quad 0.12$

$\begin{array}{ccc}0.33^{*} & -0.49^{* * *} & 0.03 \\ -0.16 & -0.26 & 0.26\end{array}$

$\begin{array}{llll}0.16 & -0.25 & -0.16 & 0.13\end{array}$

$0.31 *$

$\mathrm{C} / \mathrm{N}$ ratio (humus) nd

$0.41 * * \quad-0.26$

$\begin{array}{lll}-0.19 & -0.02 & -0.09\end{array}$

$\begin{array}{lllll}-0.17 & 0.19 & 0.13 & -0.11 & 0.59 * * *\end{array}$

$\begin{array}{ll}-0.35^{* *} & -0.61 * * * \\ -0.27 & -0.25\end{array}$

$\begin{array}{lllll}0.59 * * * & 0.14 & -0.05 & -0.07 & 0.45^{* * *}\end{array}$ 


\section{LAYER 4: 40-80 cm}

\begin{tabular}{|c|c|c|c|c|c|c|c|c|c|c|c|c|c|c|c|}
\hline & POM-C & respired-C ${ }^{*}$ & $\mathrm{~T}_{50 \text { HC_PYR }}$ & $\mathrm{T}_{50 \_\mathrm{CO} 2 \mathrm{OX}}$ & SOC & $\mathrm{C} / \mathrm{N}$ ratio (soil) & HI & $\mathrm{OI}_{\mathrm{RE} 6}$ & Clay & Sand & $\mathrm{pH}_{\text {water }}$ & CEC & MAP & MAT & $\mathrm{C} / \mathrm{N}$ ratio (inputs) \\
\hline respired-C & $0.47^{* * *}$ & & & & & & & & & & & & & & \\
\hline $\mathrm{T}_{50 \_ \text {HC_PYR }}$ & $-0.35^{*}$ & $-0.41 * *$ & & & & & & & & & & & & & \\
\hline $\mathrm{T}_{50 \_\mathrm{CO} 2 \_\mathrm{OX}}$ & -0.01 & -0.01 & 0.19 & & & & & & & & & & & & \\
\hline $\mathrm{SOC}$ & $-0.43^{* *}$ & $-0.54 * * *$ & 0.21 & $-0.49^{* * *}$ & & & & & & & & & & & \\
\hline $\mathrm{C} / \mathrm{N}$ ratio (soil) & $0.30^{*}$ & -0.17 & 0.13 & -0.21 & $0.29 *$ & & & & & & & & & & \\
\hline HI & 0.06 & -0.03 & -0.21 & -0.24 & 0.19 & 0.23 & & & & & & & & & \\
\hline $\mathrm{OI}_{\mathrm{RE} 6}$ & $-0.42 * *$ & 0.13 & 0.11 & 0.22 & -0.07 & $-0.65 * * *$ & $-0.43 * *$ & & & & & & & & \\
\hline Clay & $-0.34 *$ & -0.08 & 0.03 & 0.12 & $0.33^{*}$ & $-0.55^{* * *}$ & -0.06 & $0.62 * * *$ & & & & & & & \\
\hline Sand & $-0.42 * *$ & 0.16 & -0.12 & 0.10 & $-0.48^{* * *}$ & $0.44^{* *}$ & 0.04 & $-0.51^{* * *}$ & $-0.90^{* * *}$ & & & & & & \\
\hline $\mathrm{pH}_{\text {water }}$ & $0.46^{* * *}$ & 0.03 & -0.02 & -0.18 & 0.20 & -0.27 & 0.09 & 0.28 & $0.36^{*}$ & $-0.36^{*}$ & & & & & \\
\hline CEC & $-0.34^{*}$ & 0.13 & -0.08 & -0.02 & 0.25 & $-0.49 * * *$ & 0.05 & $0.52^{* * *}$ & $0.80 * * *$ & $-0.75 * * *$ & $0.66^{* * *}$ & & & & \\
\hline MAP & -0.25 & $-0.42^{* *}$ & 0.16 & $-0.45^{* *}$ & $0.69^{* * *}$ & $0.36^{*}$ & 0.17 & -0.13 & -0.03 & -0.12 & -0.04 & -0.07 & & & \\
\hline MAT & 0.04 & 0.09 & 0.13 & $0.50^{* * *}$ & $-0.48^{* * *}$ & $-0.28 *$ & 0.03 & 0.16 & 0.08 & 0.01 & -0.15 & -0.06 & $-0.58 * * *$ & & \\
\hline $\mathrm{C} / \mathrm{N}$ ratio (inputs) & $0.33^{*}$ & $0.30^{*}$ & -0.19 & -0.22 & -0.15 & 0.21 & -0.08 & -0.12 & $-0.31^{*}$ & 0.26 & 0.01 & -0.26 & -0.24 & -0.11 & \\
\hline $\mathrm{C} / \mathrm{N}$ ratio (humus) & 0.10 & 0.29 & -0.27 & $-0.29 *$ & 0.02 & 0.13 & 0.01 & 0.11 & 0.00 & -0.06 & $0.37 * *$ & 0.15 & -0.04 & -0.10 & $0.44 * *$ \\
\hline
\end{tabular}

LAYER 5: 80-100 cm

\begin{tabular}{|c|c|c|c|c|c|c|c|c|c|c|c|c|c|c|c|}
\hline \multirow{2}{*}{\multicolumn{16}{|c|}{ LAYER 5: $80-100 \mathrm{~cm}$}} \\
\hline & POM-C & respired-C ${ }^{*}$ & $\mathrm{~T}_{50 \_H C \_P Y R}$ & $\mathrm{~T}_{50 \_\mathrm{CO} 2 \_\mathrm{OX}}$ & SOC & $\mathrm{C} / \mathrm{N}$ ratio (soil) & $\mathrm{HI}$ & $\mathrm{OI}_{\mathrm{RE} 6}$ & Clay & Sand & $\mathrm{pH}_{\text {water }}$ & $\mathrm{CEC}$ & MAP & MAT & $\mathrm{C} / \mathrm{N}$ ratio (inputs) \\
\hline respired-C & $\overline{\text { nd }}$ & & & & & & & & & & & & & & \\
\hline $\mathrm{T}_{50 \_ \text {HC_PYR }}$ & nd & $-0.48 * *$ & & & & & & & & & & & & & \\
\hline $\mathrm{T}_{50 \_\mathrm{CO} 2 \_\mathrm{OX}}$ & nd & -0.12 & 0.08 & & & & & & & & & & & & \\
\hline $\mathrm{SOC}$ & nd & $-0.43 *$ & 0.34 & $-0.69 * * *$ & & & & & & & & & & & \\
\hline $\mathrm{C} / \mathrm{N}$ ratio (soil) & nd & -0.30 & $0.37^{*}$ & -0.26 & $0.39^{*}$ & & & & & & & & & & \\
\hline $\mathrm{HI}$ & nd & 0.17 & $-0.39 *$ & -0.30 & 0.04 & 0.00 & & & & & & & & & \\
\hline $\mathrm{OI}_{\mathrm{RE} 6}$ & nd & 0.31 & -0.18 & 0.25 & -0.29 & $-0.58^{* * *}$ & -0.14 & & & & & & & & \\
\hline Clay & nd & -0.10 & -0.11 & 0.02 & 0.14 & $-0.51^{* *}$ & 0.09 & $0.38^{*}$ & & & & & & & \\
\hline Sand & nd & 0.09 & -0.06 & 0.17 & -0.30 & $0.41^{*}$ & -0.06 & -0.29 & $-0.86 * * *$ & & & & & & \\
\hline $\mathrm{pH}_{\text {water }}$ & nd & -0.01 & -0.03 & $-0.46^{* *}$ & $0.39^{*}$ & -0.12 & 0.22 & -0.18 & $0.36^{*}$ & $-0.37^{*}$ & & & & & \\
\hline CEC & nd & 0.27 & $-0.36^{*}$ & -0.13 & 0.04 & $-0.36^{*}$ & 0.30 & 0.21 & $0.72 * * *$ & $-0.60 * * *$ & $0.64 * * *$ & & & & \\
\hline MAP & nd & -0.21 & 0.26 & -0.34 & $0.60 * * *$ & $0.46^{* *}$ & 0.05 & -0.11 & -0.30 & 0.10 & 0.04 & -0.24 & & & \\
\hline MAT & nd & -0.12 & 0.09 & $0.43 *$ & $-0.43 *$ & -0.27 & 0.13 & 0.29 & 0.27 & -0.17 & -0.24 & 0.03 & $-0.54 * *$ & & \\
\hline $\mathrm{C} / \mathrm{N}$ ratio (inputs) & nd & $0.45^{*}$ & -0.12 & -0.20 & -0.01 & -0.08 & -0.21 & 0.13 & -0.09 & -0.05 & -0.03 & -0.06 & -0.12 & -0.13 & \\
\hline $\mathrm{C} / \mathrm{N}$ ratio (humus) & nd & 0.25 & -0.07 & -0.22 & 0.13 & 0.02 & 0.04 & 0.14 & 0.27 & -0.34 & 0.14 & 0.25 & -0.06 & 0.05 & $0.41 *$ \\
\hline
\end{tabular}

${ }^{*} \mathrm{n}=31$ 

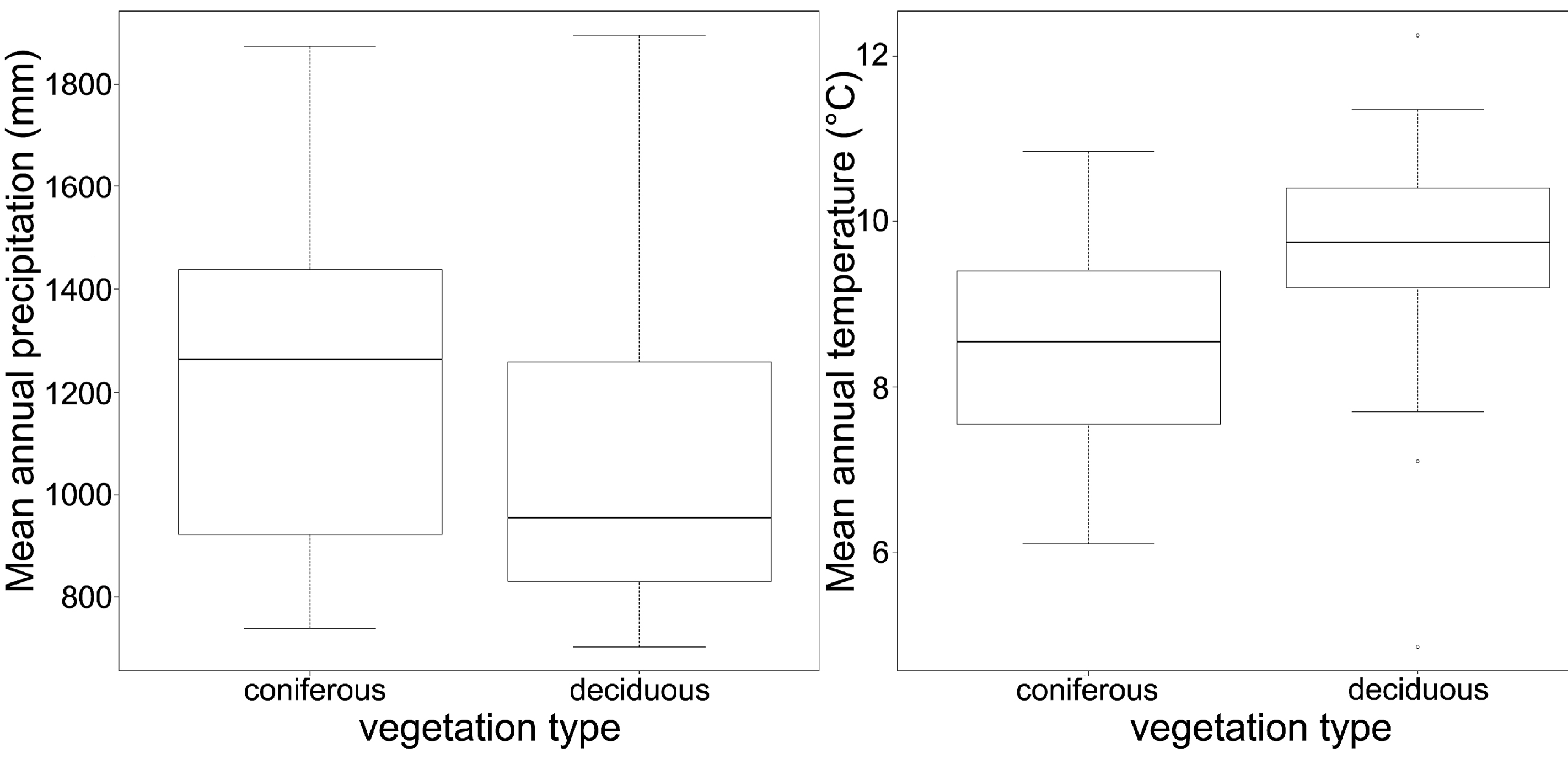